\title{
Characterization of lauryl betaine foam in the Hele-Shaw cell at high foam qualities ( $80 \%-98 \%)$
}

\author{
Asad Hassan Syed ${ }^{1} \cdot$ Nurudeen Yekeen $^{2} \cdot$ Eswaran Padmanabhan ${ }^{2} \cdot$ Ahmad Kamal Idris $^{1} \cdot$ Dzeti Farhah Mohshim $^{1}$
}

Received: 18 August 2019 / Published online: 4 June 2020

(c) The Author(s) 2020

\begin{abstract}
Lauryl betaine (LB) as an amphoteric surfactant carries both positive and negative charges and should be able to generate stable foam through electrostatic interaction with nanoparticles and co-surfactants. However, no previous attempts have been made to investigate the influence of nanoparticles and other co-surfactants on the stability and apparent viscosity of LBstabilized foam. In this study, a thorough investigation on the influence of silicon dioxide $\left(\mathrm{SiO}_{2}\right)$ nanoparticles, alpha olefin sulfonate (AOS) and sodium dodecyl sulfate (SDS), on foam stability and apparent viscosity was carried out. The experiments were conducted with the 2D Hele-Shaw cell at high foam qualities (80\%-98\%). Influence of AOS on the interaction between the $\mathrm{LB}$ foam and oil was also investigated. Results showed that the $\mathrm{SiO}_{2}$ - $\mathrm{LB}$ foam apparent viscosity decreased with increasing surfactant concentration from $0.1 \mathrm{wt} \%$ to $0.3 \mathrm{wt} \% .0 .1 \mathrm{wt} \% \mathrm{SiO}_{2}$ was the optimum concentration and increased the $0.1 \mathrm{wt} \% \mathrm{LB}$ foam stability by $108.65 \%$ at $96 \%$ foam quality. In the presence of co-surfactants, the most stable foam, with the highest apparent viscosity, was generated by AOS/LB solution at a ratio of 9:1. The emulsified crude oil did not imbibe into AOS-LB foam lamellae. Instead, oil was redirected into the plateau borders where the accumulated oil drops delayed the rate of film thinning, bubble coalescence and coarsening.
\end{abstract}

Keywords Foam stability $\cdot$ Surfactant $\cdot$ Nanoparticles $\cdot$ Lauryl betaine $\cdot$ Foam quality $\cdot$ Foam apparent viscosity

\section{Introduction}

Gas flooding has been proposed as a promising technology not only to enhance oil recovery, but also to reduce carbon emissions. Successful application of $\mathrm{CO}_{2}$ gas injection is very vital in meeting the increasing world demand for hydrocarbon, as well as, reducing carbon emissions through their capture and storage in deep geologic formations. However, gas injection usually results in poor volumetric sweep efficiency due to the low viscosity and density of the injected gas compared to the resident reservoir oil and brines (Yekeen et al. 2018a). Recently, the application of foam has been

Edited by Yan-Hua Sun

Nurudeen Yekeen

peteryekeen@yahoo.com

1 Department of Petroleum Engineering, Faculty of Geoscience and Petroleum Engineering, 32610 Seri Iskandar, Perak, Malaysia

2 Institute of Hydrocarbon Recovery, Universiti Teknologi PETRONAS, 32610 Bandar Seri Iskandar, Perak, Malaysia proven important in mitigating the challenges of viscous fingering, gravity override and channeling normally associated with gas injection. The foaming of the injected gas increases the apparent viscosity of the displacing fluid. The relative gas permeability and the gas mobility are reduced during foamed gas injection (Yekeen et al. 2017d, 2018a).

Although the potential application of foam for enhanced oil recovery is promising, the field application is still limited by the instability of the thin liquid film at the bubble's interfaces. Surface active agents, such as surfactants, have been used as the foam generating and stabilizing agents for several decades. They are also used to stabilize the emulsions (Georgieva et al. 2009). However, surfactant-stabilized foams are unstable at reservoir conditions of high temperature and in the presence of resident oil and brine in the reservoir (Yekeen et al. 2017b). The conventional foam also suffers from huge capital cost, due to surfactant adsorption on porous matrix and the unfavorable environmental impacts of the foaming chemicals (Yekeen et al. 2018a). Hence, the development of low-cost and environmentally friendly chemical formulations, for generation of stable 
foams at reservoir conditions, remains a major objective of present research.

Recently, there has been increasing interest in prospective applications of foam-based fracturing fluids in water-sensitive formations. This is due to the limitations of conventional water-based fracturing fluids. Conventional water-based fluid demonstrates low proppant-carrying capacity. The large water consumption usually results in formation damage, fracpad leakage into the reservoir and matrix close to the created fractures (Yekeen et al. 2018b). Generally, ultralow water content foam will be required for the minimization of water usage for hydraulic fracturing operations. Foam has also been studied extensively for dust suppression and dust control to mitigate the dust hazards which are severe in different industrial fields (Wang et al. 2019a, b).

The choice of lauryl betaine (LB) for foam generation was based on its unique properties as zwitterionic surfactant. These properties have been identified as high thermal stability, superb resistant to hard water and exceptional compatibility with different kinds of surfactants and co-surfactants (Cui 2014). Lauryl betaine is milder surface-active agent that is derivative of vegetables. They are more environmentally friendly foaming agent and foam boosters compared to the conventional surfactants due to their low toxicity and less irritating properties (Xiao et al. 2017). They carried both positive and negative charges and should be able to generate stable foam, through electrostatic interactions with nanoparticles and other co-surfactants.

Some attempts were made in previous studies to investigate the properties of the LB foams at various conditions. Results of Basheva et al. (2000) and Cui (2014) experiments showed that betaine foam demonstrated high stability in the presence and absence of oil. Conn et al. (2014) and Singh and Mohanty (2016) found that the synergistic blend of LB and alpha olefin sulfonate (AOS) at a ratio of 1:1 resulted in the formation of stable foam in the presence of salts. Syed et al. (2019) studied the performance of LB, when applied as foam booster for improving the bulk stability of foams generated using sodium dodecyl sulfate, alpha olefin sulfonate and Surf X (a locally produced surfactant). Their results showed that the presence of LB in the surfactant solutions improved the static stability of AOS and SDS foam. Moreover, the concentrations of Surf X required for stable foam generation decreased in the presence of LB.

However, most previous investigation of LB foams was focused on bulk foam properties and stability at low foam qualities in the absence of oil. Results of previous studies showed that bulk foam properties at static conditions cannot adequately describe foam properties in porous media (Laskaris 2015; Singh and Mohanty 2016). The mechanisms of foam generation and destruction at static conditions are entirely different from their behavior at dynamic conditions (Kapetas et al. 2016; Yekeen et al. 2018a; Singh and Mohanty 2016). To the best of authors' knowledge, the properties and apparent viscosity of LB foam in the presence of different additives, such as nanoparticles and other co-surfactants, have not been reported in any existing literature. Moreover, the influence of LB on the interaction between conventional surfactant-stabilized foam and oil is still unknown. The presence of oil in a porous system is a critical parameter that influences foam performance (OseiBonsu et al. 2015; Farajzadeh et al. 2012).

Consequently, the apparent viscosity and stability of LB foam in the liquid-filled 2D Hele-Shaw cell at high foam quality range $(80 \%-98 \%)$ was investigated in this study. Influence of $\mathrm{SiO}_{2}$ nanoparticles, SDS and AOS surfactants on the foam performance was studied. The Hele-Shaw cell is the fundamental representation of porous medium in which fluid flow behavior and interaction among fluids can be studied (Krzan et al. 2013; Osei-Bonsu et al. 2016). The HeleShaw cell used in this study permits visualization of fluid flow in two dimensions and easy determination of pressure drop for calculating foam apparent viscosity. The influence of LB on the interaction between the AOS foam and oil was examined to elucidate the mechanisms of AOS-LB foam-oil interactions in the 2D Hele-Shaw cell. Fundamental investigation of LB foam flow characteristics and stability in the 2D Hele-Shaw cell, in the absence and presence of oil, is a required step toward understanding the foam flow properties and the foam-oil interaction phenomenon in a more complex porous system.

\section{Materials and methods}

\subsection{Materials}

Two types of commercially available anionic surfactants, alpha olefin sulfonate (AOS) and sodium dodecyl sulfate (SDS), as well as one amphoteric surfactant, lauryl betaine (LB), were used in this study. The LB was obtained from Solvay Company as a solution containing $29.8 \mathrm{wt} \%$ active material. The AOS $\left(\mathrm{C}_{14-16}\right)$ and SDS were obtained from STEPAN Chemical Co. The SDS was supplied in powder form, while AOS surfactant was in liquid form. The details of the surfactants used in this study are shown in Table 1 . The brine was prepared with the concentration of $3.0 \mathrm{wt} \%$ of $\mathrm{NaCl}$ to simulate formation water. The $\mathrm{NaCl}$ was obtained from Merck Co. R\&M Chemicals. The silica nanoparticles $\left(\mathrm{SiO}_{2}\right)$ used for the study were purchased from US Research Nanomaterials Inc., USA, in white powder form with purity of $99.5 \%$. The particle size was found to be in the range of $15-20 \mathrm{~nm}$. The crude oil, used for investigating the foam-oil interaction, was from an oil company in Malaysia. The crude oil is a light oil with an API gravity of $41.37^{\circ}$, density of 
Table 1 Details of the surfactants used in this study

\begin{tabular}{|c|c|c|c|c|}
\hline Sample No. & Name of surfactant & Description of surfactant & Type of surfactant & $\begin{array}{l}\text { Active } \\
\text { percent- } \\
\text { age, } \%\end{array}$ \\
\hline 1 & $\begin{array}{l}\text { BIO TERGE AS-40 (AOS } \\
\left.\text { C }_{14-16}\right)\end{array}$ & Alpha olefin sulfonate & Anionic & 39.0 \\
\hline 2 & SDS & Sodium dodecyl sulfate & Anionic & $>93.0$ \\
\hline 3 & LB & Lauryl betaine & Amphoteric & 29.8 \\
\hline
\end{tabular}

$0.811 \mathrm{~g} / \mathrm{cm}^{3}$, and viscosity of $5.84 \mathrm{cP}$ at $25^{\circ} \mathrm{C}$. Air was used as the gas phase for the foam generation.

\subsection{Experimental procedure}

The solid surfactants and the salt sample were weighed out on mass basis (in gram) and dissolved separately in deionized water based on the desired concentrations. For the liquid surfactants, a standard solution was prepared, after which a dilution of the required concentration was then obtained from the standard solution (Yekeen et al. 2019a). The nanoparticles were then added to the solutions in stepwise fashion during the mixing process, so as to minimize the nanoparticle aggregation. The samples were then shaken for $1 \mathrm{~h}$ using an Orbital shaker and afterward sonicated for 1 $\mathrm{h}$ in a sonicator (QSonica, Q500) at a frequency of $20 \mathrm{kHz}$ and 500 watts. Similar methods have been employed in previous studies (Yekeen et al. 2019b). All the solutions were prepared with $3 \mathrm{wt} \% \mathrm{NaCl}$ solution to simulate the formation water.

Three sets of experiments were conducted in this study. The first set of experiments were conducted to determine the stability and apparent viscosity of LB-stabilized and $\mathrm{SiO}_{2}$-LB-stabilized foams. A total of 30 test samples with LB concentration above critical micelle concentration (CMC) (0.1 wt \% and $0.3 \mathrm{wt} \%$ for LB, respectively) and 0.05 wt $\%, 0.10 \mathrm{wt} \%, 0.15 \mathrm{wt} \%$ and $0.20 \mathrm{wt} \% \mathrm{SiO}_{2}$ concentration at three foam qualities $(80 \%, 87 \%$ and $96 \%)$ were prepared and investigated. The second set of experiments were conducted to determine the AOS-LB and SDS-LB foam stability and apparent viscosity. A total of 35 test samples with surfactant concentration above the CMC (0.1 wt \% LB, 0.5 wt $\%$ AOS and $0.5 \mathrm{wt} \% \mathrm{SDS})$, five surfactant/LB ratio (100\% AOS, $90 \%$ AOS: $10 \%$ LB, $70 \%$ AOS:30\% LB, 100\% SDS and $90 \%$ SDS: $10 \%$ LB), and seven foam qualities (80\%, $84 \%, 87 \%, 90 \%, 93 \%, 96 \%$ and $98 \%$ ) were investigated. The static stability was estimated from the bubble size distribution at constant foam quality $(90 \%)$ and four different time intervals $(0,60,120 \mathrm{~min}$ and $24 \mathrm{~h})$.

The foam properties (stability and apparent viscosity) were estimated from the foam bubble size distribution and pressure drop during foam flow in the first and second experiments. In the third set of experiments, the influence of LB on AOS foam-oil interaction as a function of time ( 0 and $60 \mathrm{~min}$ ) and two foam qualities (80\% and 95\%) was studied. All the experiments were conducted at room temperature of $25^{\circ} \mathrm{C}$ and ambient pressure.

\subsubsection{Determination of surfactant critical micelle concentration (CMC)}

The critical micelle concentration (CMC) of the surfactant was measured by the electrical conductivity method using a conductivity meter (S230 Seven Compact, Mettler Toledo). To determine the CMC, $50 \mathrm{~mL}$ of an approximately 0.5 wt $\%$ aqueous stock solution of the surfactant was prepared. Twenty-five milliliters of deionized water was pipetted into a $100-\mathrm{mL}$ beaker, and then, $0.5 \mathrm{~mL}$ of stock solution was pipetted into water and stirred, and the conductivity was recorded. A plot of conductivities versus the surfactant concentration was made. The CMC was estimated as the surfactant concentration at the cross point of the two straight lines obtained from the plots. The use of conductivity values for determining surfactant CMC is based on the assumptions that there is variation of electrical conductance of aqueous ionic surfactant solutions at the surfactant concentration above and below the CMC. Surfactant monomers are expected to behave as strong electrolytes at concentrations below CMC, while partial ionization of the micelles occurred at concentrations above the CMC (Domínguez et al. 1997). For conventional surfactant CMC determination from surface tension, a dynamic surface analyzer (DSA 25) was used to measure the surface tension as functions of surfactant concentrations. The CMC of the surfactant was the surfactant concentration at the inflexion point of the curve. No noticeable changes in surface tension were observed after the CMC. All measurements were conducted at least three times, and the average values were calculated.

\subsubsection{Foam flow dynamics in a liquid-filled 2D Hele-Shaw cell}

The apparent viscosity of the foam was calculated from the pressure drop estimated as the foam propagated through the 
liquid-filled 2D Hele-Shaw cell at different foam qualities. The Hele-Shaw cell was prepared from two glass plates having a length of $31 \mathrm{~cm}$ and a width of $20 \mathrm{~cm}$. The thickness of the glass plate was $0.5 \mathrm{~cm}$. Inlet and outlet were engraved on one of the glass plates. The permeability was created by placing a gasket of $0.01 \mathrm{~cm}$ between the glass plates. Similar Hele-Shaw cell was designed and used by Osei-Bonsu et al. $(2015,2016)$ in previous studies.

The setup was made up of two syringe pumps (NE-1000). One pump was used to inject air, while the other one was to inject the solution samples. The pumps were first calibrated with a TERUMO syringe. The foam was generated by simultaneous injection of air and the surfactant solution which converge at the T-junction point. Similar method of foam generation was employed by Chevallier et al. (2019) in recent study. The pre-generated foam was injected into the brine-filled ( $3 \mathrm{wt} \% \mathrm{NaCl}$ ) Hele-Shaw cell. An ELVEFLOW ${ }^{\circledR}$ microfluidic pressure sensor was used to measure the differential pressure as the foam moves through the Hele-Shaw cell. The reading was taken when the pressure was stable, and the obtained pressure difference was then used to calculate the foam apparent viscosity using Eq. (1) (Osei-Bonsu et al. 2015, 2016; Osei-Bonsu 2017; Yan et al. 2006; Yekeen et al. 2017b, d).

$\mu_{\text {foam.app }}=\frac{K \Delta p}{v_{\text {fluid }} L}=\frac{b^{2} \Delta p}{12 v_{\text {fluid }} L}$

where $\mu_{\text {foam.app }}$ is the apparent viscosity of foam; $K=\frac{b^{2}}{12}$ is the permeability of the cell, $b$ is the gap thickness of the Hele-Shaw cell in $\mathrm{cm}^{2} ; v_{\text {fluid }}$ is the velocity of the foam; $L$ is the length of the Hele-Shaw cell in $\mathrm{cm}$ and $\Delta p / L$ is the pressure gradient across the Hele-Shaw cell. The procedure was repeated to determine the apparent viscosities of $\mathrm{SiO}_{2}-\mathrm{LB}$, AOS-LB, and SDS-LB foams at different foam qualities.

For the static stability experiments, the pre-generated foam was injected into the Hele-Shaw cell at constant foam quality (90\%). The dynamics of foam in the 2D Hele-Shaw cell and its evolution was recorded at different time intervals using a high-resolution camera. The images were then converted to 8-bit greyscale images, and the image analysis was done using the plugin of Image ${ }^{\circledR}$ software namely particle analyzer. A fixed area of $1.5 \mathrm{~cm} \times 1.5 \mathrm{~cm}$ was studied. The cutoff bubble size in the image analysis was set to $0.02 \mathrm{~cm}^{2}$ such that any bubble which was less than $0.02 \mathrm{~cm}^{2}$ was disregarded. All foams were generated at constant salinity conditions $(3 \mathrm{wt} \% \mathrm{NaCl})$. The experimental setup of the liquid-filled 2D Hele-Shaw cell used in this study is shown in Fig. 1a. The schematic of the Hele-Shaw cell is shown in Fig. 1b.

\subsubsection{Foam-oil interaction in the Hele-Shaw cell}

The foam-oil interaction was investigated in the 2D HeleShaw cell with the design quite different from the liquid filled. The Hele-Shaw cell was constructed using two glass plates having a length of $20 \mathrm{~cm}$, a width of $2.54 \mathrm{~cm}$ and a depth of $0.05 \mathrm{~cm}$. Inlet and outlet were engraved on one of the glass plates, while the oil inlet was engraved in middle of the glass plate. The permeability between the plates was created by placing glass beads of a diameter of $500 \mu \mathrm{m}$ at the corners of the glass plates. The foam was generated by simultaneous injection of air and the solution sample using a tee junction. The pre-generated foam was injected into the Hele-Shaw cell. The liquid injection rate was fixed at $0.1 \mathrm{~mL} / \mathrm{min}$. The air was injected at different flow rates to produce foam qualities of $80 \%$ and $95 \%$. The oil injection started once the 2D Hele-Shaw cell was completely filled with the foam. $0.5 \mathrm{~mL}$ of oil was injected manually at a rate of $0.5 \mathrm{~mL} / \mathrm{min}$ using a syringe. The oil was injected from the edge of the glass plate which was engraved as an inlet. Once the required quantity of oil was injected, the interaction between the foam and oil was studied. During the experiment, only a small area of the Hele-Shaw cell was observed where foam-oil interaction had taken place because of the limitation of the microscopic study. The image was captured
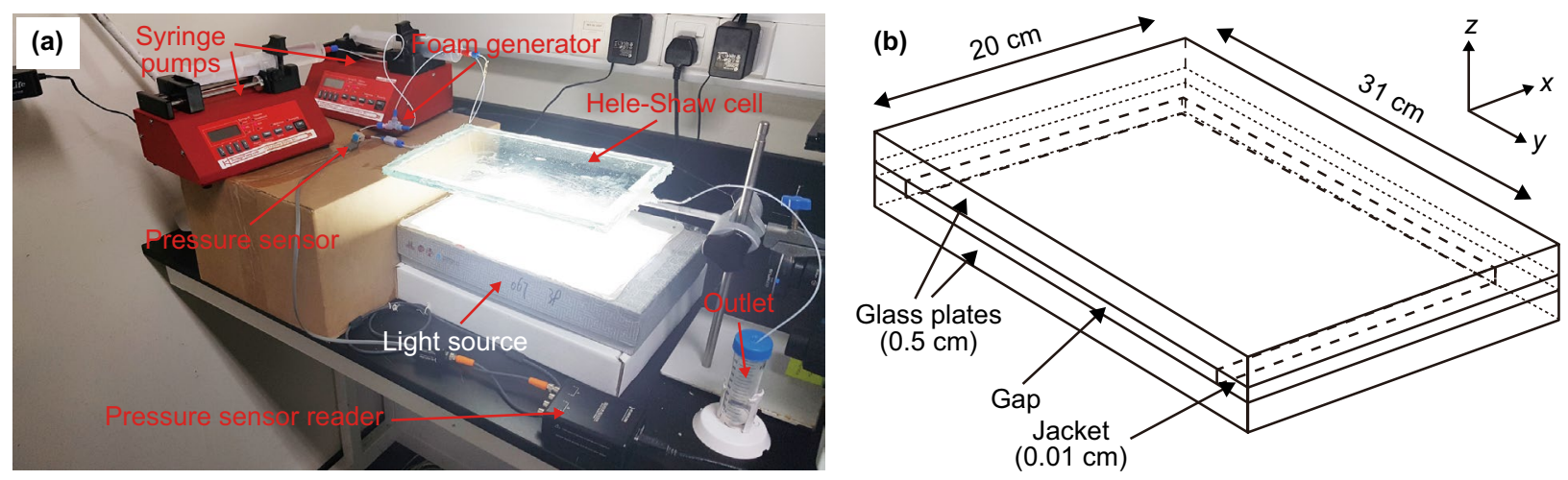

Fig. 1 a Experimental setup of the liquid-filled 2D Hele-Shaw cell used in this study and b schematic of the Hele-Shaw cell used in this study 
using an Olympus IX53 inverted microscope (Olympus Corporation, Japan). Influence of LB on AOS foam-oil interaction was investigated. The experimental setup of the foam-oil interaction in the 2D Hele-Shaw cell is shown in Fig. 2.

\section{Results and discussion}

\subsection{Critical micelle concentration (CMC) of the surfactant}

The plot of conductivity versus surfactant concentration and surface tension versus surfactant concentration presented in Fig. 3a-f shows a break at the CMC. The CMC of the surfactants were obtained at the cross point of two lines. The CMC of the LB was obtained as $0.6 \mathrm{wt} \%$, that of AOS and SDS were obtained as approximately $0.1 \mathrm{wt} \%$ and $0.2 \mathrm{wt} \%$, respectively. The results for CMC of different surfactants from conductivity versus concentration and surface tension versus concentration were found to be consistent. These values are consistent with the literature (Rafati et al. 2018; Xu et al. 2009; Yarveicy and Javaheri 2017).

The CMC of the surfactants were determined in order to identify the minimum surfactant concentration required for foam generation. Generally, surfactant-stabilized foam generation and stability depends on the CMC of the surfactant (Kumar and Mandal 2017). The CMC is the surfactant concentration at which aggregation of surfactant molecules and formation of micelles occur (Yekeen et al. 2019b). Any extra surfactant molecules added to the system beyond the CMC are involves in micelle formation. Hence, the surface tension are not expected to decrease beyond the CMC (Yekeen et al. 2019a).

The distribution, adsorption and aggregation of surfactant molecules at the gas-liquid interface of the foam plays a

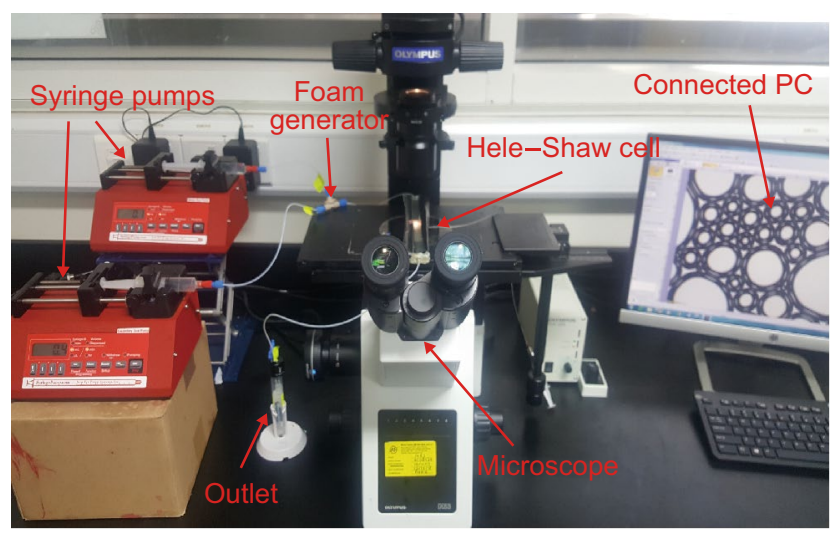

Fig. 2 Experimental setup used to study foam-oil interaction in the 2D Hele-Shaw cell very significant role in stabilizing foam lamella. This can be attributed to the formation of stable liquid films and increasing interfacial viscosity which prevent liquid drainage and bubble coalescence (Yekeen et al. 2019a). It has been further emphasized that the presence of stable micelles is crucial for the formation of durable foam, since organized surfactant molecules can only be formed at the foam lamellae whenever the surfactant concentrations exceeded the CMC (Pandey et al. 2003). Likewise, the surfactant concentration beyond the CMC is essential for the generation of stable foam and for the foam propagation at dynamic conditions in porous formations (Hanamertani et al. 2018; Mannhardt and Svorstøl 2001). Hence, the determination of surfactant CMC is required for fundamental understanding of the critical properties of surfactant-stabilized foams such as generation, stability and propagation.

Pandey et al. (2003) investigated the influence of surfactant concentration on foam stability in order to clarify the function of micelles in foam generation and stability. From the results of their experiments, no noticeable change was observed in foam stability at the surfactant concentration below the CMC. However, a considerable increase in foam stability occurred when the surfactant concentration beyond the CMC value was used. Surfactant concentrations above CMC $(0.1 \mathrm{wt} \%$ and $0.3 \mathrm{wt} \%)$ were chosen to investigate the influence of LB concentration on foam generation and stability.

\subsection{Influence of foam quality on the apparent viscosities of $\mathrm{LB}$ and $\mathrm{SiO}_{2}$-LB foams}

Figure 4 shows the apparent viscosities of LB and nanoparticles-LB stabilized foams as a function of differing foam qualities. The results show that the foam apparent viscosity decreases with increasing foam quality. This result is in agreement with the results of previous studies. The foam apparent viscosity decreases with increasing foam quality at the wet-foam regime and after the transition foam quality (the maximum foam quality for obtaining the optimum foam apparent viscosity), which has been reported in previous studies (Khatib et al. 1988; Yekeen et al. 2017d, 2018b). Foams can be categorized as wet foam $(52 \%-74 \%$ foam quality), dry foam (74\%-96\% foam quality) and mist foam (when the foam quality is beyond 96\%) (Hutchins and Miller 2005; Yekeen et al. 2018b). The foam quality regime investigated in this study $(80 \%, 87 \%$, and $96 \%)$ is within the dry foam regime. Hence, the foam flow behavior is expected to be dominated by bubble coalescence.

Foam texture has been identified as the main parameter influencing foam apparent viscosity (Osei-Bonsu et al. 2016; Falls et al. 1988; Yan et al. 2006). The foam morphology at different concentrations of $\mathrm{LB}$ and $\mathrm{SiO}_{2}$ nanoparticles was observed from the bubble size and segmented images of the 

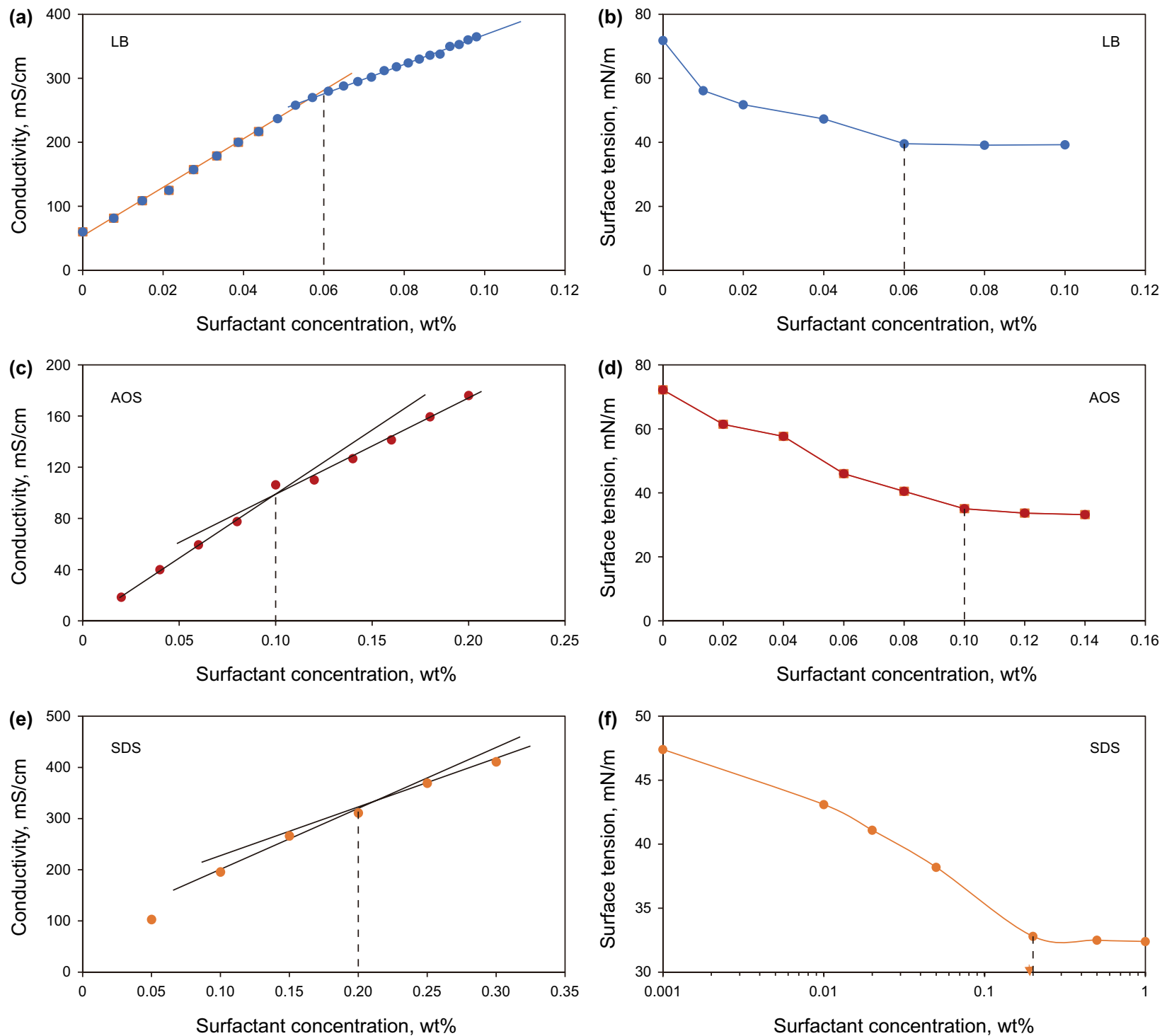

Fig. 3 A plot of conductivity versus concentration and surface tension versus concentration for determination of CMC of various surfactants: a LB from conductivity results, b LB from surface tension results, c AOS from conductivity results, $\mathbf{d}$ AOS from surface tension results, e SDS from conductivity results and $\mathbf{f}$ SDS from surface tension results

foam at different foam qualities presented in Figs. 5, 6, and 7. The results indicate that finer bubbles and more bubbles per unit area (higher bubble density) were generated at lower foam quality. The histogram of the bubble size distribution in Fig. 8 further confirms that the bubble size increases while the number of bubbles per unit area decreases with the increasing foam quality.

The result is consistent with the literature (Ma et al. 2012; Osei-Bonsu et al. 2016; Ettinger and Radke 1992; Yekeen et al. 2017a, b). This phenomenon (the decreasing foam stability and apparent viscosity with increasing foam quality) has been attributed to increasing frequency of bubble collisions and Oswald ripening due to high percentages of dispersed gas per unit volume of the foaming solutions
(Osei-Bonsu et al. 2016). The higher gas volume per unit volume of surfactant solutions at higher foam quality results in dynamic and recurrent interaction within the foamy fluids, consequently increasing the rate of gas diffusion from lamellae, bubble coalescence and coarsening (Fei et al. 2017; Yekeen et al. 2018b).

Generally, the apparent viscosity of the $\mathrm{LB}$ and $\mathrm{SiO}_{2}-\mathrm{LB}$ foams obtained in this study was found to be quite low, ranging between $1.85 \mathrm{cP}$ and $5.30 \mathrm{cP}$. This can be attributed to the low permeability of the 2D Hele-Shaw cell (gap thickness of $0.01 \mathrm{~cm}$ ) used in this study. Previous studies showed that the foam apparent viscosity decreases with the increasing gap thickness of the Hele-Shaw cell (Osei-Bonsu et al. 2016). For foam flowing in a porous system, the degree of 


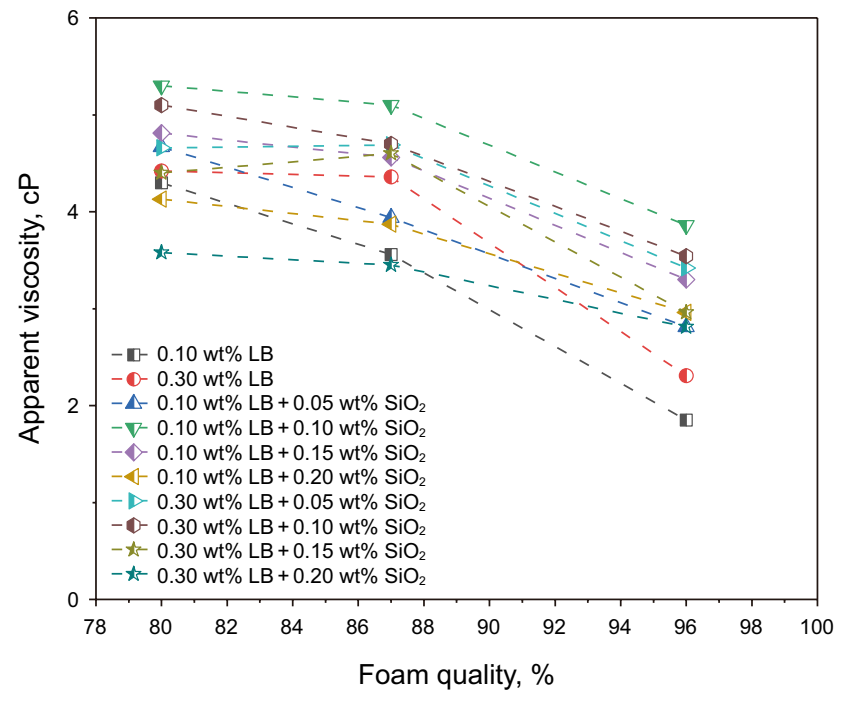

Fig. 4 Comparison of the apparent viscosity of LB- and $\mathrm{SiO}_{2}$-LB-stabilized foams

contacts and interactions between two adjacent bubbles, the bubbles and plateau borders, as well as, the bubbles and the walls of the confining medium increase with reduced medium permeability. The stress on the confining bubbles in the 2D Hele-Shaw cell and the apparent strain rate are increased due to the closer packing of the thin liquid films between bubbles, consequently, reducing foam flow resistance and apparent viscosity (Osei-Bonsu et al. 2016; Cantat 2013; Gu and Mohanty 2014).

The low apparent viscosity of $\mathrm{SiO}_{2}$ - $\mathrm{LB}$ foam can also be attributed to the low foamability of nanoparticle-stabilized foam. Successful generation of nanoparticle-stabilized foam involved a flow rate (shear rate) higher than the required shear rate for surfactant stabilized foam (Yekeen et al. 2018a). It was very difficult to generate foam in the presence of nanoparticles at the same flow rate used for surfactantstabilized foam in this study. Generally, the LB foam viscosity decreased with increasing foam quality but increased with increasing surfactant concentration from $0.1 \mathrm{wt} \%$ to $0.3 \mathrm{wt} \%$. For instance, at the highest foam quality $(96 \%)$, the apparent viscosity of the foam increased from $1.85 \mathrm{cP}$ to $2.31 \mathrm{cP}(24.86 \%)$. Smaller bubbles with high bubble density were also observed from the morphology of foam generated using $0.3 \mathrm{wt} \% \mathrm{LB}$ compared to $0.1 \mathrm{wt} \% \mathrm{LB}$ foam (Fig. 5).

As the LB concentration increases, the concentration of surfactants in the bulk solution increases due to availability of more surfactant molecules. This results in a rapid rate of surfactant migration to the foam lamellae and high surfactant density at the gas-liquid interface of foam, resulting in higher resistance to flow, high foam stability and higher foam apparent viscosity (Bournival et al. 2014; Karakashev and Manev 2003; Yekeen et al. 2017c). However, significant increases in apparent viscosity and foam stability were demonstrated by the $\mathrm{SiO}_{2}$-LB-stabilized foam. At the highest foam quality (96\%), the apparent viscosity of the $0.1 \mathrm{wt} \%$ LB foam increased from $1.85 \mathrm{cP}$ to $2.85 \mathrm{cP}(53.2 \%)$ while that of the $0.3 \mathrm{wt} \% \mathrm{LB}$ foam increased from $2.31 \mathrm{cP}$ to 3.42 $\mathrm{cP}(48 \%)$ in the presence of $0.05 \mathrm{wt} \% \mathrm{SiO}_{2}$ nanoparticles. The apparent viscosity of the $0.1 \mathrm{wt} \% \mathrm{LB}$ foam increased from $1.85 \mathrm{cP}$ to $3.86 \mathrm{cP}(108.65 \%)$ while that of the $0.3 \mathrm{wt} \%$ LB foam increased from $2.31 \mathrm{cP}$ to $3.54 \mathrm{cP}(53.25 \%)$ at the highest foam quality (96\%) and in the presence of $0.1 \mathrm{wt} \%$ $\mathrm{SiO}_{2}$ nanoparticles.

The apparent viscosity of the $0.1 \mathrm{wt} \% \mathrm{LB}$ foam at the foam quality $(96 \%)$ increased from $1.85 \mathrm{cP}$ to $3.3 \mathrm{cP}(77.4 \%)$ while that of the $0.3 \mathrm{wt} \% \mathrm{LB}$ foam increased from $2.31 \mathrm{cP}$ to $2.96 \mathrm{cP}(28 \%)$ in the presence of $0.15 \mathrm{wt} \% \mathrm{SiO}_{2}$ nanoparticles. In the presence of $0.2 \mathrm{wt} \% \mathrm{SiO}_{2}$ nanoparticles and at the highest foam quality (96\%), the apparent viscosity of the $0.1 \mathrm{wt} \% \mathrm{LB}$ foam increased from $1.85 \mathrm{cP}$ to $2.96 \mathrm{cP}(59 \%)$ while that of $0.3 \mathrm{wt} \% \mathrm{LB}$ foam increased from $2.31 \mathrm{cP}$ to $2.81 \mathrm{cP}(21.6 \%) .0 .1 \mathrm{wt} \%$ of $\mathrm{SiO}_{2}$ concentration was found to be the optimum concentration in improving the apparent viscosity of LB foams at $0.1 \mathrm{wt} \%$ and $0.3 \mathrm{wt} \%$, respectively. In the $\mathrm{LB}-\mathrm{SiO}_{2}$ foam, the nanoparticles serve as foam stabilizer by their adsorption and aggregation at the foam lamellae to prevent film thinning through liquid drainage, bubble coalescence and coarsening. The nanoparticles are solids with a high surface area for promoting electrostatic interaction and are expected to be stable at realistic reservoir conditions.

The bubble size distributions of $\mathrm{SiO}_{2}$ - $\mathrm{LB}$ foams in Figs. 5, 6 and 7 show thicker lamellae due to adsorption and aggregation of $\mathrm{SiO}_{2}$ nanoparticles at thin liquid films. Histogram of the bubble size distributions in Fig. 9 confirmed that the $\mathrm{SiO}_{2}$-LB bubbles were smaller, compacted and there were many bubbles per total area than the LB-stabilized bubbles. The interface of $\mathrm{SiO}_{2}$ - $\mathrm{LB}$ bubbles resisted deformation due to the enhanced surface viscoelasticity resulting from adsorption of nanoparticles on the bubble surfaces as the bubbles interacted with adjacent bubbles, plateau borders, and the confining walls of the porous media (Yekeen et al. 2017b; Sun et al. 2014). Hence, the resistance to flow was restricted and the foam apparent viscosity increased.

However, the surface-active complex formed between $0.1 \mathrm{wt} \% \mathrm{SiO}_{2}$ and $0.1 \mathrm{wt} \% \mathrm{LB}$ were found to improve the foam apparent viscosity and bubble durability more than the surface-active complex formed between $0.1 \mathrm{wt} \% \mathrm{SiO}_{2}$ and $0.3 \mathrm{wt} \%$ LB. $0.1 \mathrm{wt} \%$ of $\mathrm{SiO}_{2}$ was found to be the optimum concentration among the tested $0.05 \mathrm{wt} \%, 0.15$ wt $\%$ and $0.2 \mathrm{wt} \% \mathrm{SiO}_{2}$ concentration with $\mathrm{LB}$. Increasing the concentration above $0.1 \mathrm{wt} \%$ of $\mathrm{SiO}_{2}$ did not result in an increase in the foam apparent viscosity. This result suggests the existence of the maximum LB concentration for optimum accumulation of surface-active species, maximum foam stability, as well as, higher apparent viscosity. 


\section{Foam quality}

$80 \%$
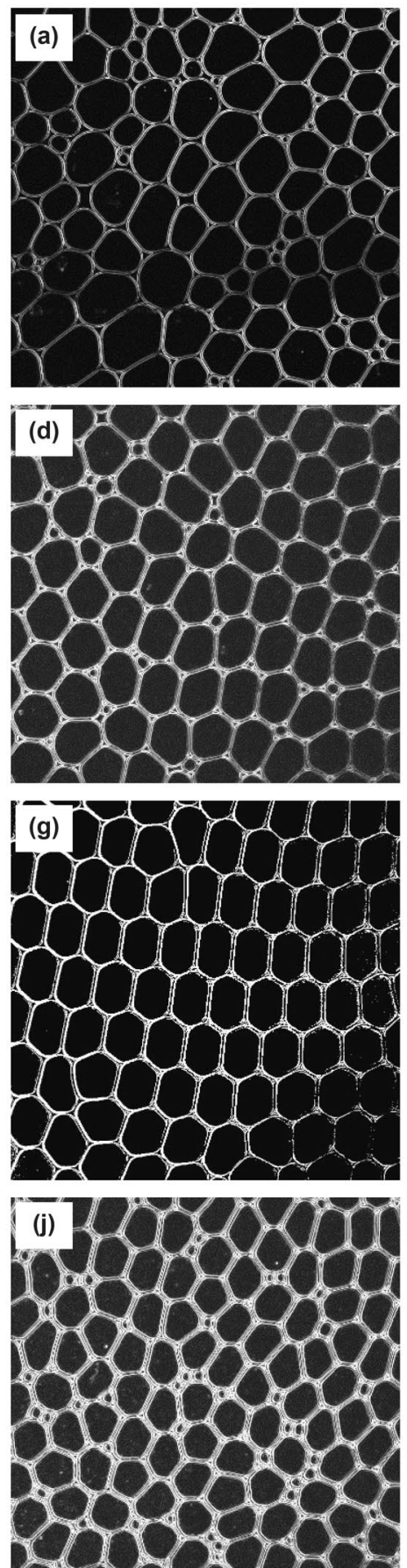

$87 \%$
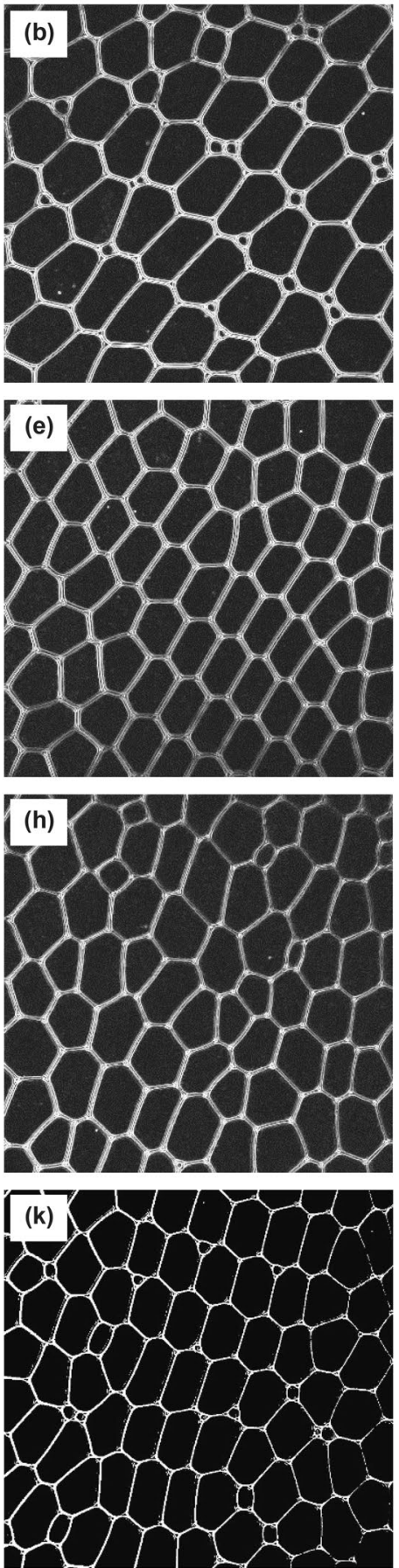

$96 \%$

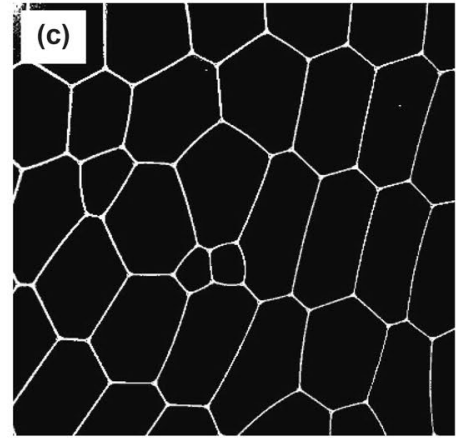

$0.10 w t \%$ LB

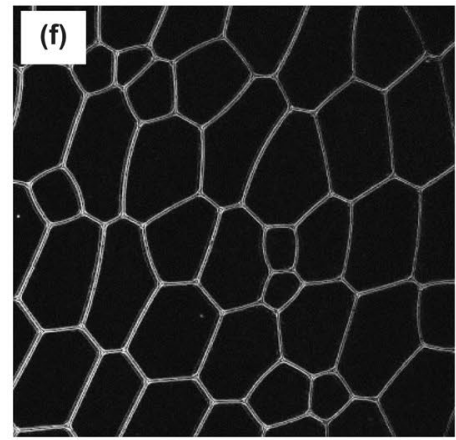

$0.10 w t \%$ LB +

$0.10 \mathrm{wt} \% \mathrm{SiO}_{2}$

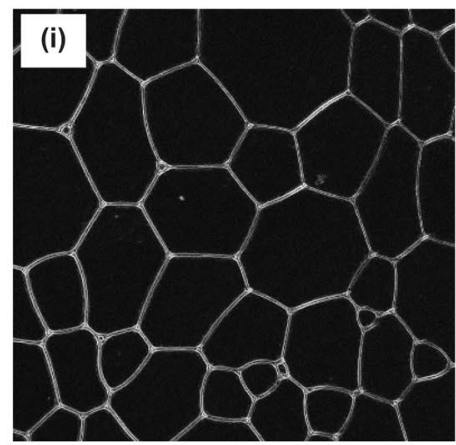

$0.30 w t \%$ LB

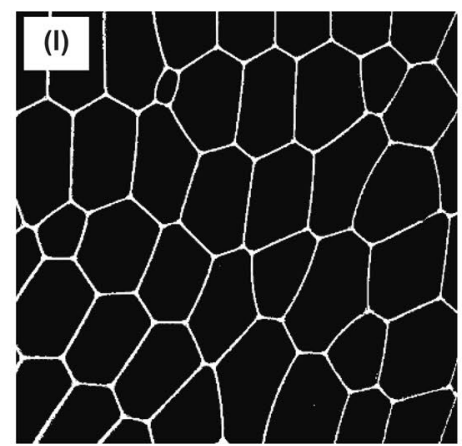

$0.30 \mathrm{wt} \% \mathrm{LB}+$ $0.10 \mathrm{wt} \% \mathrm{SiO}_{2}$

Fig. 5 Bubble size distributions at different foam qualities for a-c $0.1 \mathrm{wt} \% \mathrm{LB}$ foam, $\mathbf{d}-\mathbf{f} 0.1 \mathrm{wt} \% \mathrm{LB}+0.10 \mathrm{wt} \% \mathrm{SiO}{ }_{2}$ foam, $\mathbf{g}-\mathbf{i} 0.3 \mathrm{wt} \% \mathrm{LB}$ foam, and $\mathbf{j}-\mathbf{l} 0.3 \mathrm{wt} \% \mathrm{LB}+0.10 \mathrm{wt} \% \mathrm{SiO}_{2}$ foam

Beyond the maximum LB concentration, the increasing surfactant concentration did not improve the foam generation because there is no improvement in the extent of surfactant adsorption and accumulation at the gas-liquid interface of foam. 


\section{Foam quality}

$80 \%$
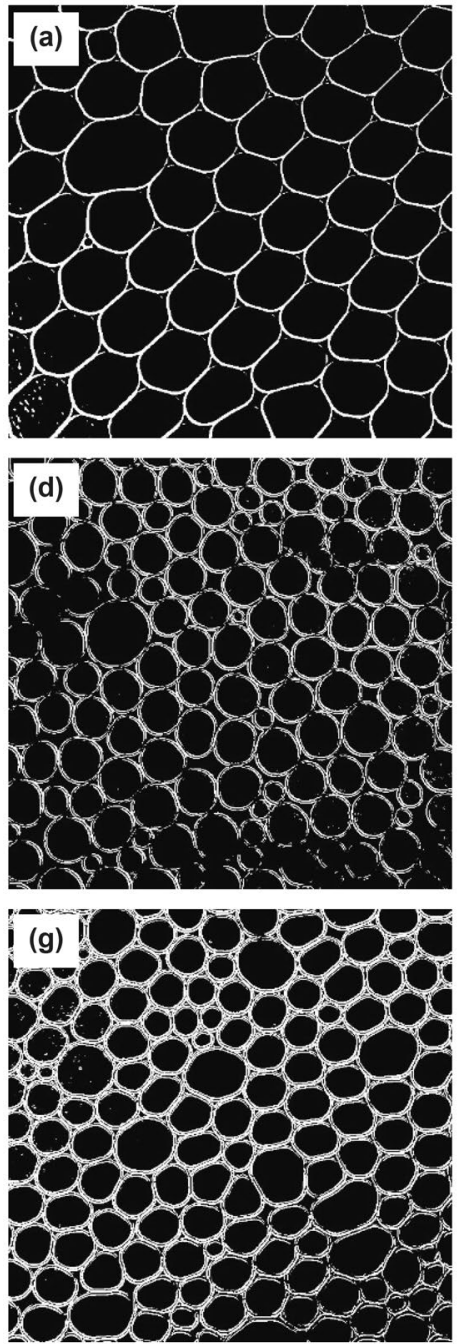

$87 \%$
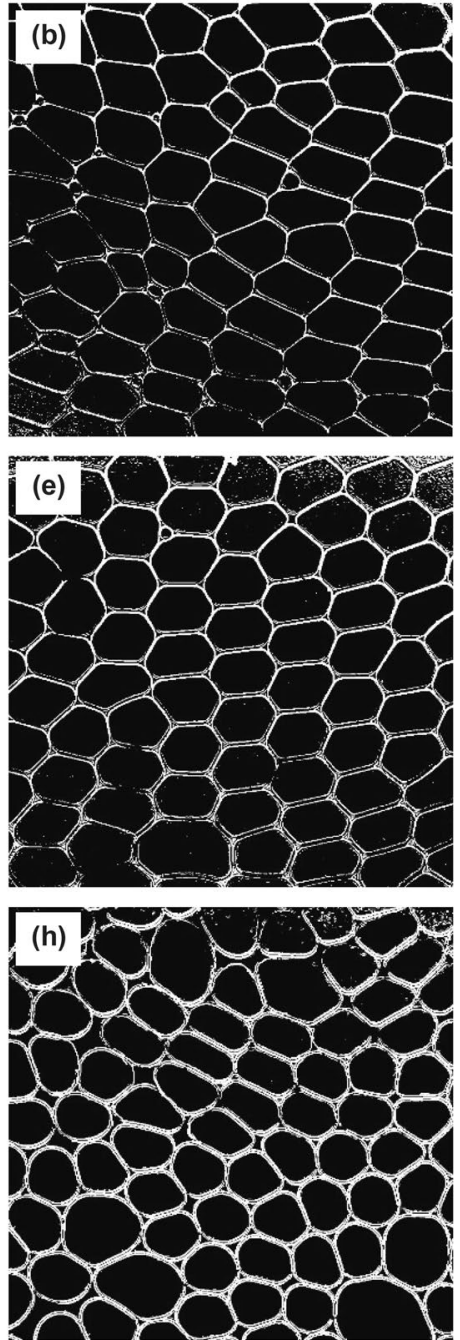

$96 \%$

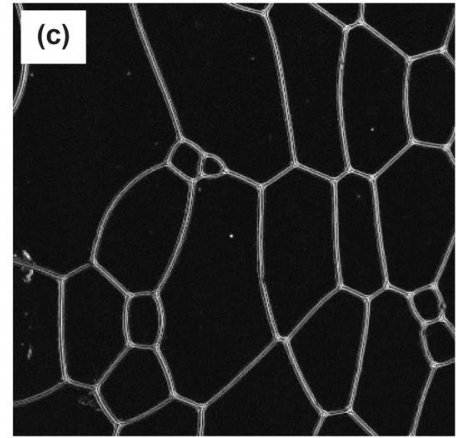

$0.10 w t \%$ LB + $0.05 \mathrm{wt} \% \mathrm{SiO}_{2}$

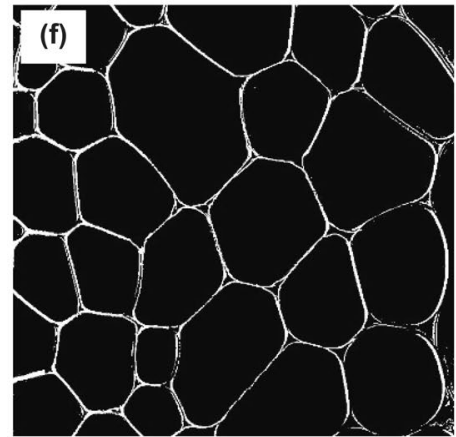

$0.10 w t \%$ LB + $0.15 \mathrm{wt} \% \mathrm{SiO}_{2}$

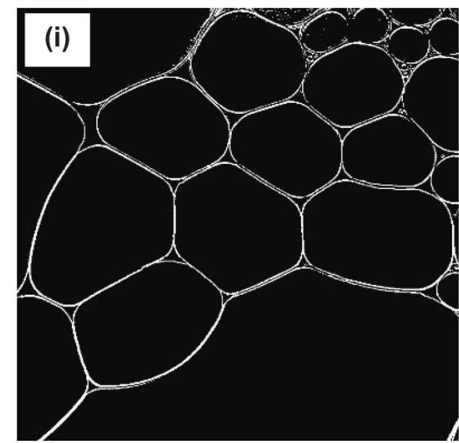

$0.10 w t \%$ LB + $0.20 \mathrm{wt} \% \mathrm{SiO}_{2}$

Fig. 6 Bubble size distributions at different foam qualities for a-c $0.1 \mathrm{wt} \% \mathrm{LB}+0.05 \mathrm{wt} \% \mathrm{SiO}_{2}$ foam, $\mathbf{d}-\mathbf{f} 0.1 \mathrm{wt} \% \mathrm{LB}+0.15 \mathrm{wt} \% \mathrm{SiO}{ }_{2}$ foam, and $\mathbf{g}-\mathbf{i} 0.1 \mathrm{wt} \% \mathrm{LB}+0.20 \mathrm{wt} \% \mathrm{SiO}_{2}$ foam

\subsection{Static stability of AOS-LB and SDS-LB foams}

Figure 10 shows the states of AOS-LB and SDS-LB foams in the 2D Hele-Shaw cell at different time intervals $(0$, $60,120 \mathrm{~min}$ and $24 \mathrm{~h}$, respectively) and constant foam quality (90\%). Generally, the use of LB as foam booster when blended with anionic surfactants (AOS and SDS) had a positive effect on the foam static stability at different surfactant/LB ratios, consequently, reducing the rate of liquid drainage, bubbles coalescence and coarsening. The foams were denoted by abbreviations A 91, A 100, S 91, A 73, and S 100, signifying different surfactant/LB ratios as presented in Table 2. It can be inferred from the bubble size distribution in Fig. 10 that the individual surfactant solution foam ruptured quickly compared to the LB blended surfactant solution foam. A 91 surfactant solution, consisting of $90 \%$ AOS and $10 \%$ LB, generated the most stable foam followed by A 100 (100\% AOS) surfactant solution. The surfactant solutions S 100 (100\% SDS) and A 73 (70\% AOS and 30\% LB) had the highest rate of foam rupture after $24 \mathrm{~h}$ as compared to S 91, A 100 and A 91 .

The static stability of foams generated by different surfactant solutions in the Hele-Shaw cell was in order of: A $91>$ A $100>$ S $91>$ A $73>$ S 100. The blend of anionic and amphoteric surfactant resulted in a denser surfactant monolayer and potentially higher film stability (Wang et al. 2017). Similar improvement in foam static stability, due to the blending of amphoteric surfactant with anionic 


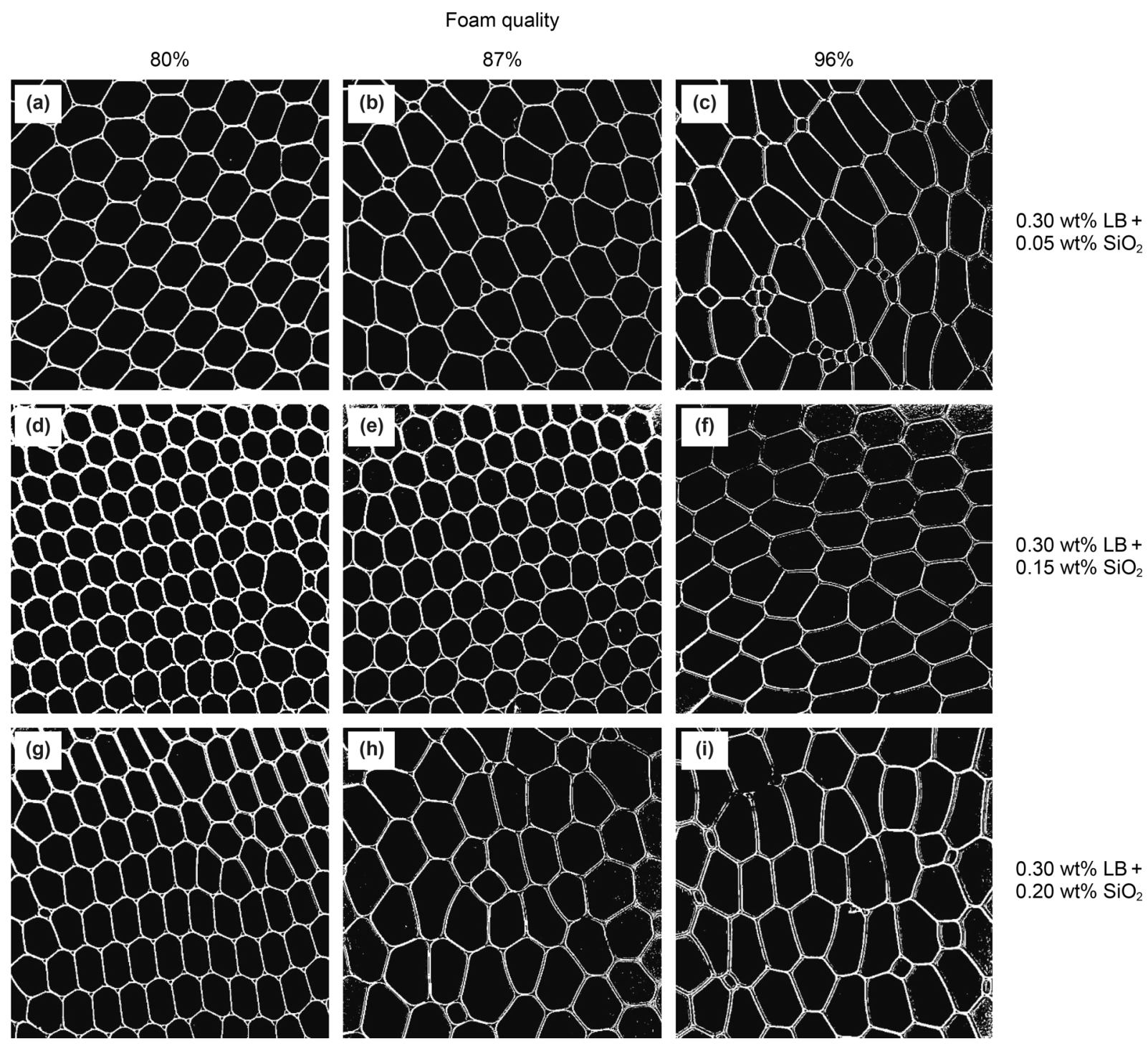

Fig. 7 Bubble size distributions at different foam qualities for a-c $0.3 \mathrm{wt} \% \mathrm{LB}+0.05 \mathrm{wt} \% \mathrm{SiO}_{2}$ foam, $\mathbf{d}-\mathbf{f} 0.3 \mathrm{wt} \% \mathrm{LB}+0.15 \mathrm{wt} \% \mathrm{SiO}{ }_{2}$ foam, and $\mathbf{g}-\mathbf{i} 0.3 \mathrm{wt} \% \mathrm{LB}+0.20 \mathrm{wt} \% \mathrm{SiO}_{2}$ foam

surfactant as foam booster, has also been reported by other researchers (Basheva et al. 2000; Osei-Bonsu et al. 2015).

\subsection{Apparent viscosity of AOS-LB and SDS-LB foams in the 2D Hele-Shaw cell}

The apparent viscosity of foam generated by different surfactant solutions is presented in Fig. 11. During foam propagation in the Hele-Shaw cell, the individual surfactant solution A 100 generated higher foam apparent viscosity compared to S 100 solution. The results showed that the AOS-based foam produced the highest foam apparent viscosity at very high-foam quality as compared to the SDSbased foam. However, a blend of LB and AOS surfactant solution generally generated higher foam apparent viscosity compared to individual surfactant solution foam. The foam performance based on the apparent viscosity in the HeleShaw cell was in order of: A 91>A 100> S 91>A 73>S 100 . This result is consistent with static foam stability results in the Hele-Shaw cell.

Generally, the improvement in apparent viscosity of AOS foam and SDS foam in the presence of LB was very significant at high foam qualities. The apparent viscosity of AOS foam increased by $16 \%$ (at $90 \%$ and $93 \%$ foam quality) and by $40 \%$ (at $98 \%$ foam quality) when blended with LB surfactant at the surfactant/LB ratio of 9:1. For the SDS foam, the apparent viscosity of the conventional foam increased by almost $16 \%, 26 \%$, by $46 \%$ and $70 \%$ at foam qualities of $90 \%$, $93 \%, 96 \%$ and $98 \%$, respectively. 

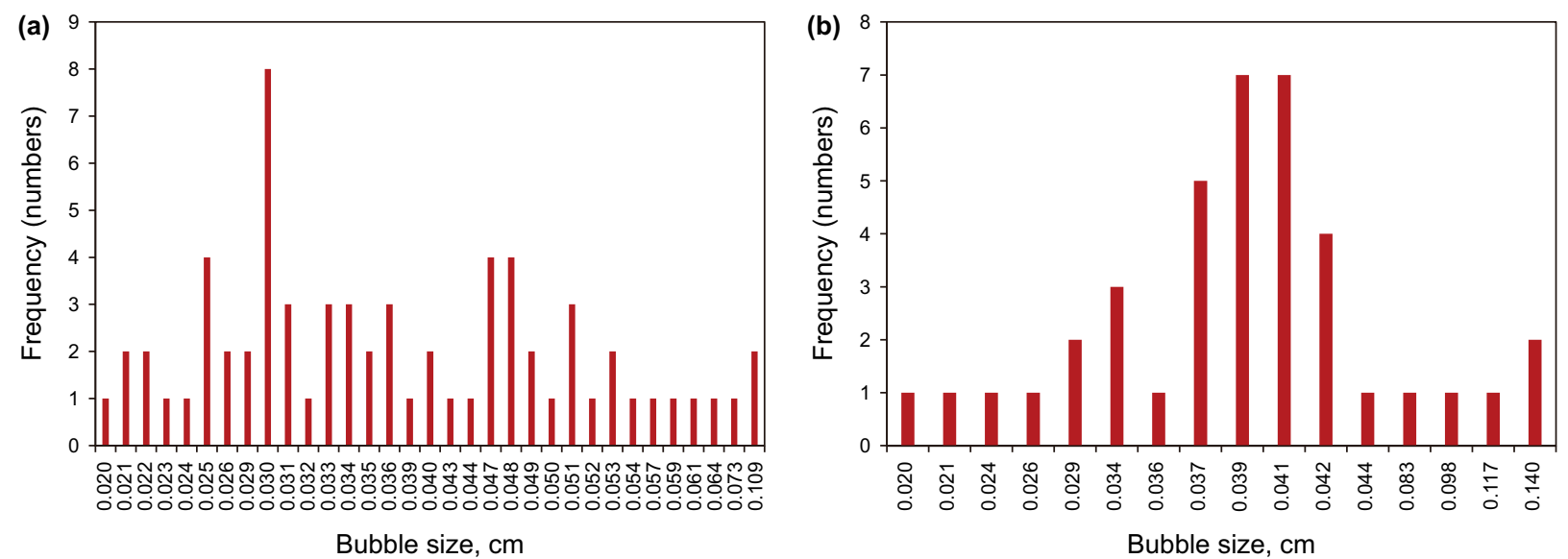

Fig. 8 Histogram representation for bubble size distribution of LB foam ( $0.1 \mathrm{wt} \% \mathrm{LB})$ at a $80 \%$ foam quality and b $87 \%$ foam quality showing the decreasing foam stability with increasing foam quality
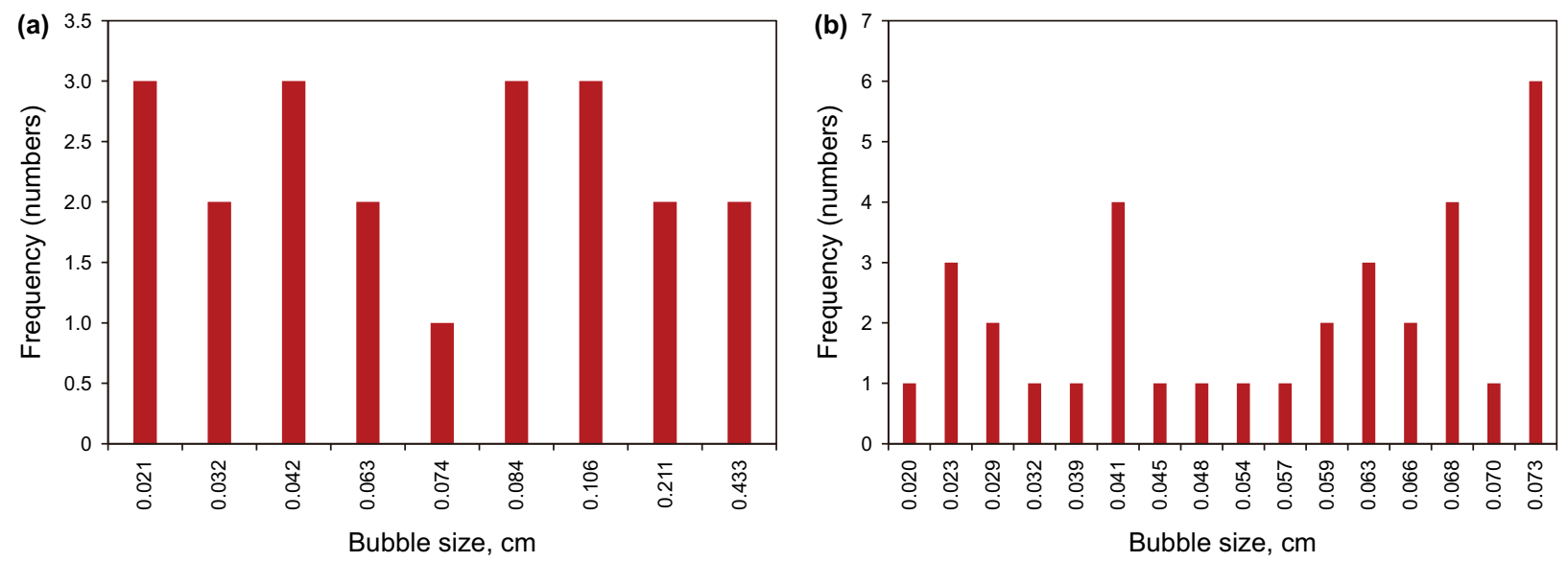

Fig. 9 Histogram representation for bubble size distributions of a $\mathrm{LB}$ foam $(0.1 \mathrm{wt} \% \mathrm{LB})$ and $\mathbf{b} 0.1 \mathrm{wt} \% \mathrm{LB}+0.10 \mathrm{wt} \% \mathrm{SiO}_{2}$ foam at $96 \%$ foam quality

But, when the AOS surfactant was blended with LB at the surfactant/LB ratio of 7:3, Fig. 11 shows that the apparent viscosity of the AOS-LB foam was much lower than that of the AOS foam at all foam qualities investigated. This result was similar to the influence of LB concentration on the apparent viscosity of LB-stabilized foams reported earlier. The surface-active complex formed between $0.1 \mathrm{wt} \% \mathrm{SiO}_{2}$ and $0.1 \mathrm{wt} \% \mathrm{LB}$ was found to improve the foam apparent viscosity better than $0.1 \mathrm{wt} \%$ $\mathrm{SiO}_{2}$ and $0.3 \mathrm{wt} \% \mathrm{LB}$. The result confirmed the existence of the optimum surfactant concentration for maximum stability of LB foam beyond which the foam stability decreased with increasing percentage of LB.

Figure 11 further shows that the apparent viscosity of AOS-LB and SDS-LB foams did not decrease with increasing foam quality as observed for the LB stabilized and $\mathrm{SiO}_{2}$-LB stabilized foams. Instead, the optimum foam quality for maximum apparent viscosities of AOS-LB and SDS-LB foams occurred beyond $80 \%$, the minimum foam quality investigated in this study.

In order to identify the optimum foam quality for maximum apparent viscosities of AOS-LB and SDS-LB foams, the foam apparent viscosities were determined at seven different foam qualities. The optimum foam qualities corresponding to the maximum apparent viscosities of foams generated by the blend of LB and surfactant solutions are presented in Fig. 12. The maximum apparent viscosities were obtained between $90 \%$ and $93 \%$ for all tested foam qualities. Compared to the $\mathrm{SiO}_{2}$ - $\mathrm{LB}$ foam, results of this study showed a considerable increase in foam apparent viscosity with increasing foam quality for AOS-LB and 


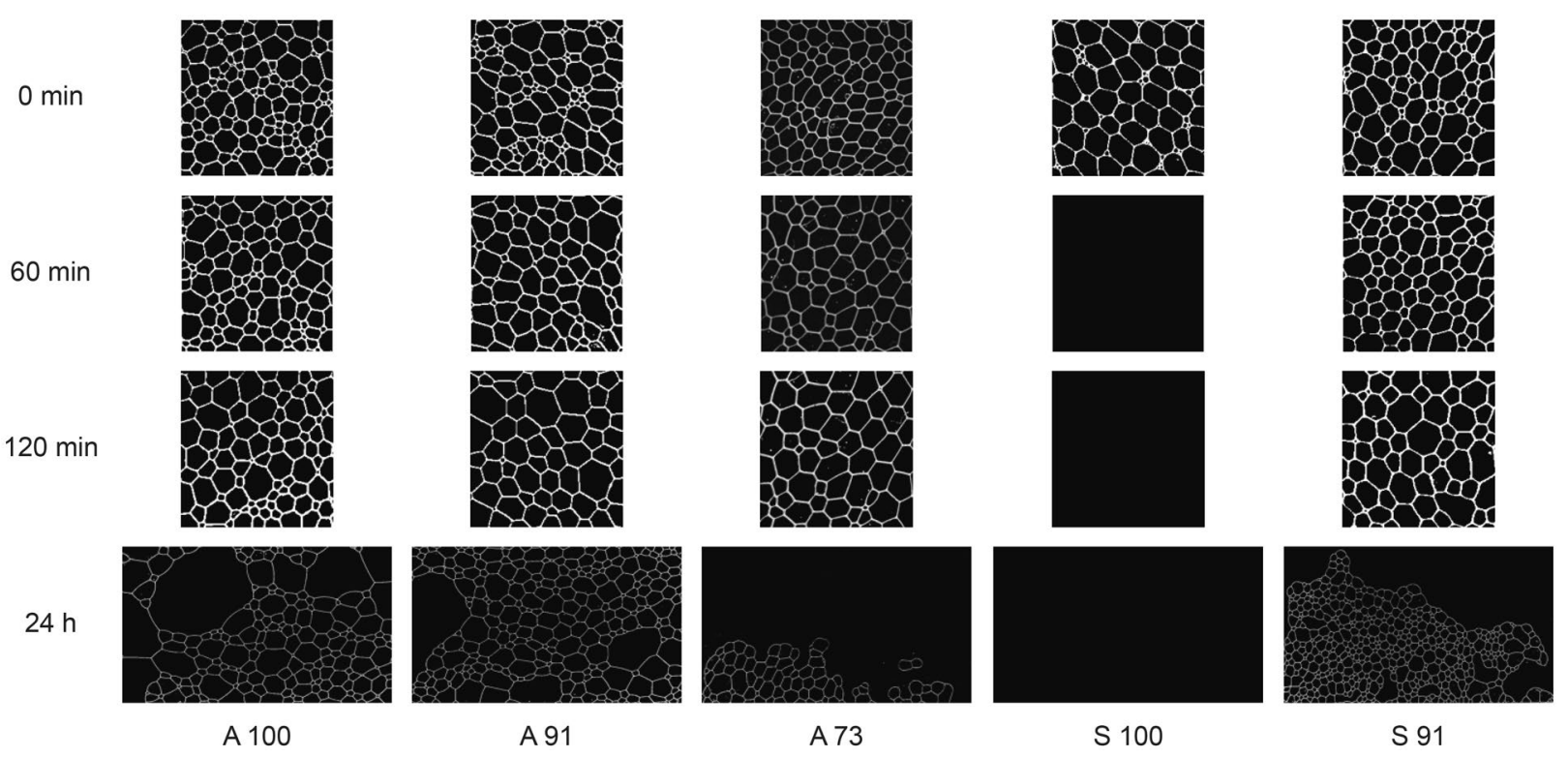

Fig. 10 A 100, A 91, A 73, S 100 and S 91 surfactant/LB generated foams inside the Hele-Shaw cell at different time intervals (black represents gas whereas white represents foam lamellae)

Table 2 Surfactant/LB solution ratios used for foam generation

\begin{tabular}{lllll}
\hline Sample No. & Label & Base surfactant & Foam booster & $\begin{array}{l}\text { Sur- } \\
\text { factant/ } \\
\text { LB ratio }\end{array}$ \\
\hline 1 & A 100 & AOS & - & - \\
2 & A 91 & AOS & LB & $9: 1$ \\
3 & A 73 & AOS & LB & $7: 3$ \\
4 & S 100 & SDS & - & - \\
5 & S 91 & SDS & LB & $9: 1$ \\
\hline
\end{tabular}

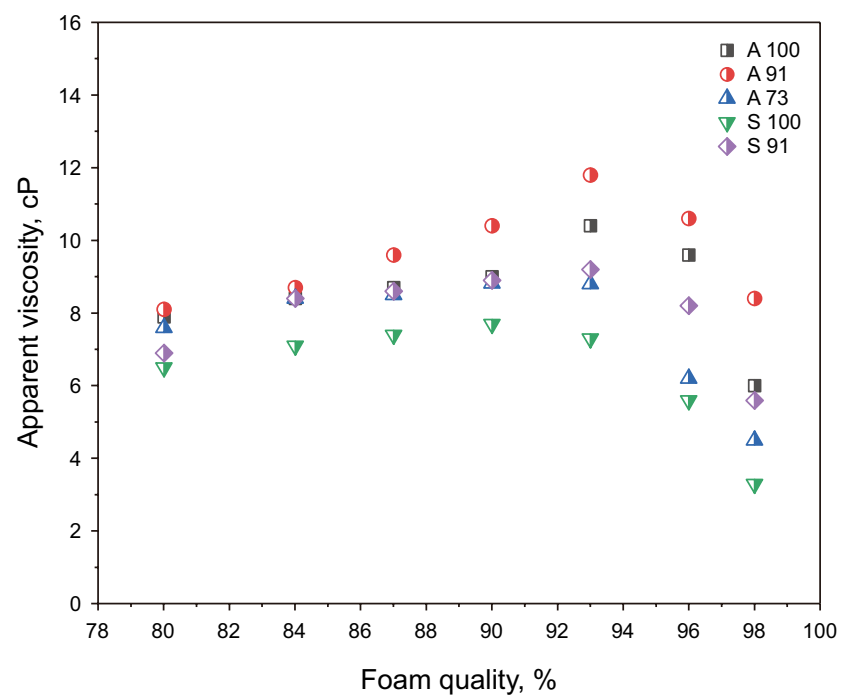

Fig. 11 Apparent viscosity of foams generated by different surfactant/ LB solutions in the Hele-Shaw cell at different foam qualities

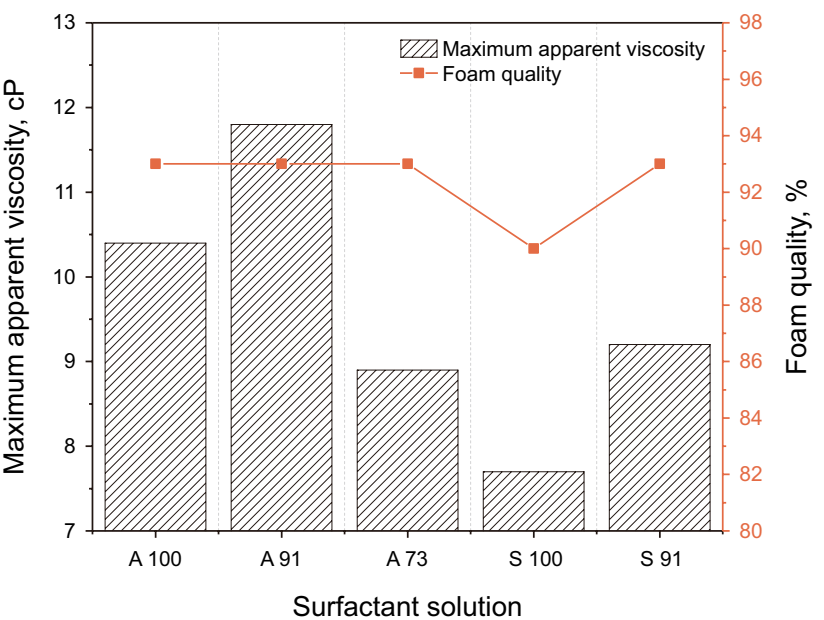

Fig. 12 Maximum apparent viscosity of foam generated by different surfactant/LB solutions

SDS-LB foams until the highest foam apparent viscosity was reached.

Results of previous study showed that high foam apparent viscosity can be obtained at high foam qualities (Osei-Bonsu et al. 2016). It was hypothesized that higher quality foam could demonstrate higher apparent viscosity, lower mobility, higher resistance to flow and deformation due to their nonspherical and non-uniform morphology, as well as, higher dissipation during flow in porous system, compared to the wet foams (Hutzler et al. 2004; Osei-Bonsu et al. 2016; Cantat 2013; Kraynik 1988). 
The increasing foam apparent viscosity with the addition of LB at the higher foam quality as compared to the surfactant solution without LB could be attributed to the elastic films generated by the addition of an amphoteric surfactant solution. The synergistic interaction between the anionic and the amphoteric surfactant molecules resulted in formation of a denser surfactant monolayer and potentially higher film stability (Wang et al. 2017). This was also verified by measuring the surface tension of the individual surfactant solution A 100 and the mixed surfactant solution A 91 using a KRUSS Drop Shape Analyzer DSA 25. The A 100 surfactant solution had a surface tension of $30.41 \mathrm{mN} / \mathrm{m}$, whereas the A 91 surfactant solution had produced the surface tension of 29.53 $\mathrm{mN} / \mathrm{m}$. Basheva et al. (2000) reported that the presence of betaine in the blended surfactant solution potentially increased the capillary pressure of the foam films. Similar phenomenon improved the stability of the foam and its apparent viscosity even at higher foam qualities beyond $90 \%$ in this study. The increase in maximum apparent viscosity of the conventional foam in the presence of foam booster as compared to the individual surfactant solution have also been reported in previous studies (Cui 2014; van der Bent 2014).

\subsection{Interaction between LB foam and oil in the 2D Hele-Shaw cell}

Previous studies have shown that oil, especially lighter components in oil (lower chain hydrocarbons), have a detrimental effect on the static and dynamic stability of foam (Yekeen et al. 2017a, d; Schramm and Novosad 1992, 1990; Xiao et al. 2017; Rafati et al. 2018; Simjoo et al. 2013; Farajzadeh et al. 2012; Vikingstad et al. 2005; Farzaneh and Sohrabi 2015; Babamahmoudi and Riahi 2018). Bubble coalescence, coarsening and foam rupture can result from the entering and spreading of oil into the foam lamellae and plateau borders. The invaded oil can exist in foam structures as emulsions or as a continuous phase and can results in weakening and detachment of the foam lamellae and plateau borders (Yekeen et al. 2017d; Rafati et al. 2018).

The phenomenon of foam-oil interaction and destabilization are usually described by four criteria. These criteria are known as the entering coefficient $(E)$, spreading coefficient $(S)$, bridging coefficient $(B)$ and the lamella number $(L)$. The formulae for calculating these parameters are given in Eqs. (2)-(5) (Rafati et al. 2018; Simjoo et al. 2013; Duan et al. 2014). Positive values of entering coefficient $(E)$, spreading coefficient $(S)$ and bridging coefficient $(B)$ show the high tendency of the oil to invade, penetrate and be dispersed, as well as, bridge the foam lamellae. Imbibition of the emulsified oil into the foam lamellae could occur when the lamellae number are exceeded (Rafati et al. 2018).
$E=\sigma_{\mathrm{w} / \mathrm{g}}+\sigma_{\mathrm{w} / \mathrm{o}}-\sigma_{\mathrm{o} / \mathrm{g}}$

$S=\sigma_{\mathrm{w} / \mathrm{g}}-\sigma_{\mathrm{w} / \mathrm{o}}-\sigma_{\mathrm{o} / \mathrm{g}}$

$B=\sigma_{\mathrm{w} / \mathrm{g}}^{2}+\sigma_{\mathrm{w} / \mathrm{o}}^{2}-\sigma_{\mathrm{o} / \mathrm{g}}^{2}$

$L=\frac{R_{\mathrm{o}} \sigma_{\mathrm{w} / \mathrm{g}}}{R_{\mathrm{p}} \sigma_{\mathrm{w} / \mathrm{o}}}$

where $\sigma_{\mathrm{w} / \mathrm{g}}$ is the water-gas surface tension, $\sigma_{\mathrm{o} / \mathrm{g}}$ is the surface tension between gas and oil while $\sigma_{\mathrm{w} / \mathrm{o}}$ is the interfacial tension between water and oil. In Eq. (5), $R_{\mathrm{o}}$ is the oil droplet radius and $R_{\mathrm{p}}$ is the plateau border radius.

The extent of interactions between the thin-liquid interface of the foam and the invaded oil phase will determine the stability of the foam in the presence of oil. This interaction was investigated for AOS foam and AOS-LB foam in the 2D Hele-Shaw cell in order to visualize the effect of LB on the conventional foam stability in the presence of oil. The phenomenon of foam-oil interaction was investigated at two foam qualities ( $80 \%$ and $95 \%$ ). The microscopic images for AOS foam-oil interaction at $80 \%$ and 95\% foam qualities are presented in Figs. 13 and 14. At $80 \%$ foam quality, entering and spreading of oil in the form of the continuous phase into the lamellae and plateau borders of AOS foam was observed in the Hele-Shaw cell (Fig. 13a, b). As time progresses, the invaded oil enters the foam film region and propagates to the plateau region; the oil further penetrates and spreads on the foam lamellae to bridge the lamellae causing lamellae detaching and collapsing (Fig. 13c, d). This incident ultimately resulted in bubble coalescence and foam rupture due to the merger of two smaller bubbles into larger bubbles (Fig. 13e, f).

Similar observations were made for foam generated at $95 \%$ foam quality (Fig. 14). However, at higher foam quality, the lamella became weakened and ruptured quickly due to the rapid rate of entering and penetration of oil at the gas/liquid interface (Fig. 14 a, b). Pseudo emulsion films thinning and foam rupture occurred during the propagation of AOS foam in the Hele-Shaw cell due to the penetration and spreading of oil over the foam lamellae and plateau borders.

The microscopic images of the interaction between $\mathrm{A}$ 91 surfactant foam and the crude oil in the 2D Hele-Shaw cell at $80 \%$ and $95 \%$ foam quality are presented in Figs. 15 and 16. Some formation of macro-emulsion from the invaded continuous oil phase was observed at $95 \%$ foam quality (Fig. 16). Entering of the oil into the foam films and propagation of the oil toward the foam films was also observed at the two foam qualities. The movement of oil through the foam film toward the plateau region could be 


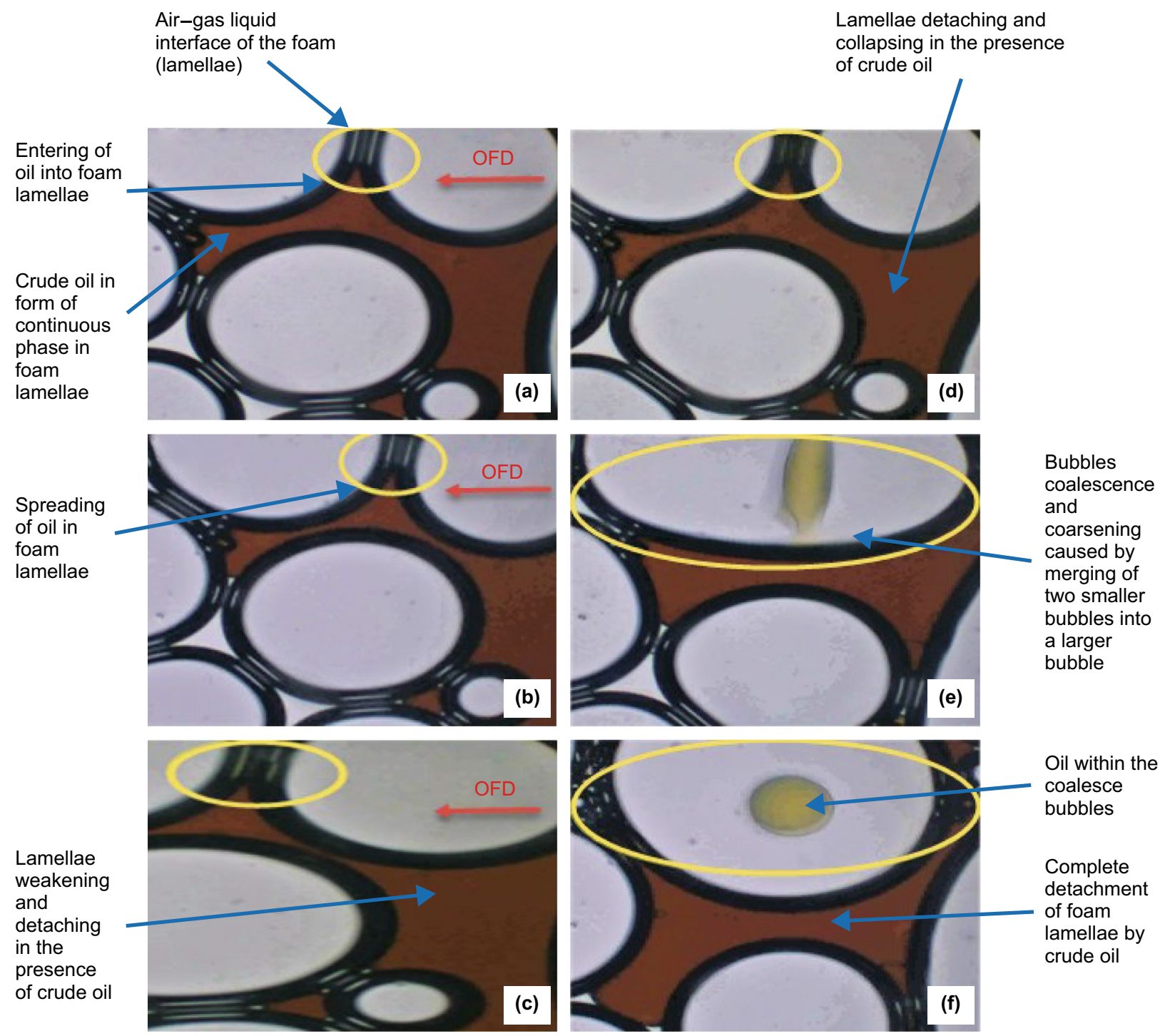

Fig. 13 Microscopic images of A 100 surfactant foam in the presence of oil at $80 \%$ foam quality showing $\mathbf{a}$, $\mathbf{b}$ entering and spreading of crude oil into the foam film, $\mathbf{c}, \mathbf{d}$ lamella weakening, detachment and collapsing due to complete invasion of the foam film by the crude oil, and $\mathbf{e}, \mathbf{f}$ bubble rupture and coarsening in the presence of crude oil. OFD with arrow represents the oil flow direction

clearly seen in the foam images. However, the foam lamellae did not get ruptured in the presence of LB as foam booster at $80 \%$ and $95 \%$ foam quality. The spreading of the oil at several portions of the foam lamellae (gas/water interface of the foam) was prevented as time progresses.

Figures 15 and 16 show that for the AOS-LB solution at a surfactant/LB ratio of 9:1, the emulsified crude oil did not imbibe into the AOS-LB foam lamellae even at foam quality of $95 \%$. Instead, the emulsified oils were redirected into the plateau borders where the accumulated oil drops delay the rate of film thinning, bubble coalescence and coarsening as well as foam rupture. Decreasing the rate of film thinning due to accumulation of oil at plateau borders of durable foams has been observed in previous studies
(Koczo et al. 1992; Simjoo et al. 2013; Aveyard et al. 1994; Jin et al. 2016; Farzaneh and Sohrabi 2015; Yekeen et al. 2017d; Rafati et al. 2018; Nikolov et al. 1986). This phenomenon has been reported to be responsible for stability of such foams.

The static stability of the foam-oil interaction was also monitored as a function of time to further explain the phenomenon of foam-oil interaction in the absence and presence of LB. Figure 17 shows the state of AOS-stabilized foam in the presence of crude oil in the 2D Hele-Shaw cell at $80 \%$ and $95 \%$ foam qualities immediately after foam generation and at $60 \mathrm{~min}$ after generation. The stability of AOS-LB foam is presented in Fig. 18. It can be observed from Figs. 17 and 18 that the crude oil demonstrated strong 
Entering and dispersion of oil from plateau borders into the air-gas liquid interface

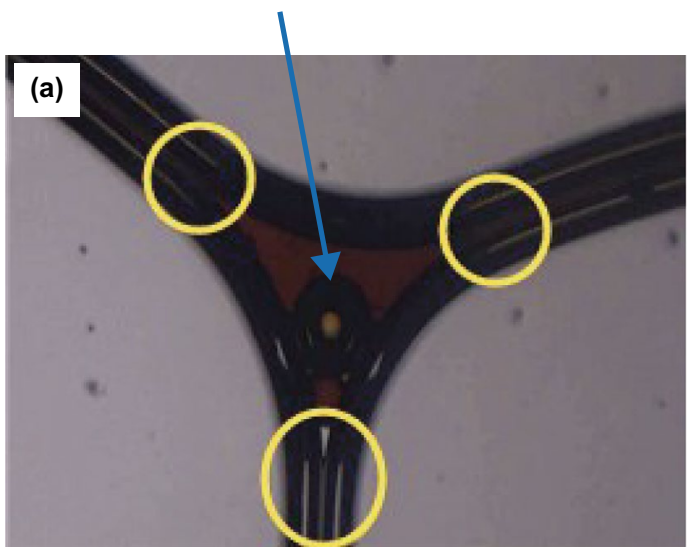

Pseudo emulsion films thinning and foam rupture by the invaded crude oil

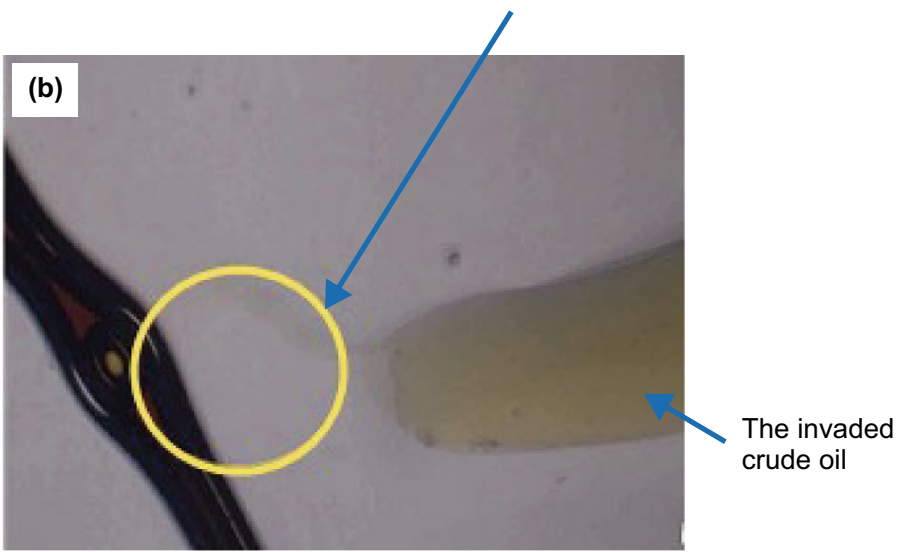

Fig. 14 Microscopic image of A 100 surfactant foam at 95\% foam quality in the presence of oil showing a migration of oil from plateau borders into foam film and $\mathbf{b}$ pseudo emulsion films thinning and foam rupture by the invaded crude oil
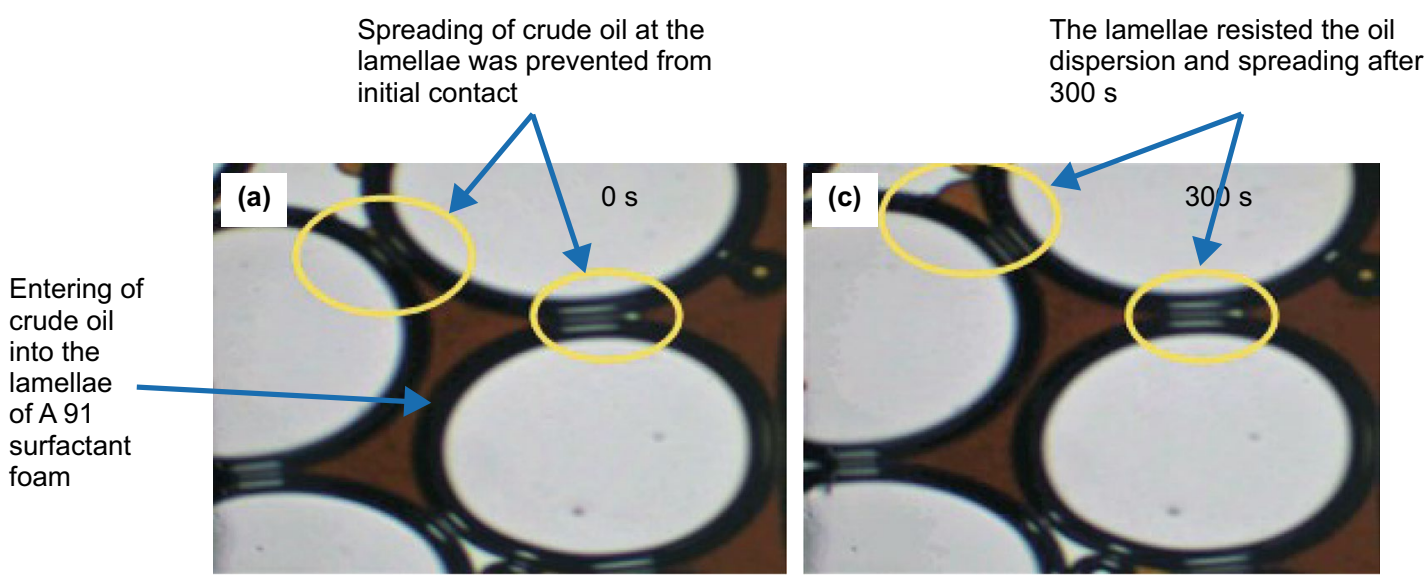
$300 \mathrm{~s}$
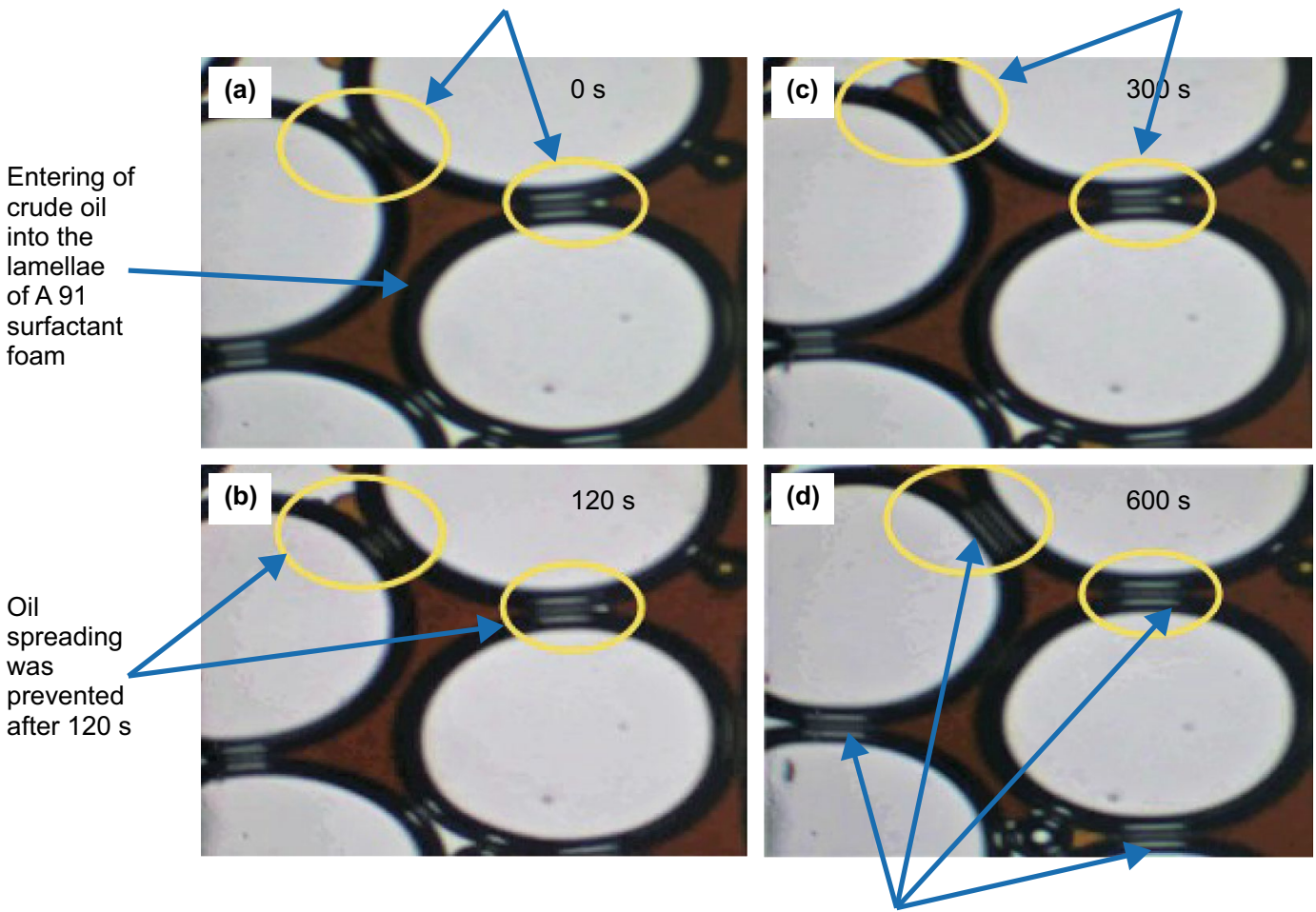

Microscopic image after $600 \mathrm{~s}$ showing that weakening, detachment and collapse of lamellae was prevented in presence of lauryl betaine.

Fig. 15 A 91 surfactant foam in the presence of oil at $80 \%$ foam quality showing that a oil entering the foam film and moving toward plateau but unable to spread at the gas-liquid interface from initial contact, $\mathbf{b}$ spreading of oil at the lamellae prevented after $120 \mathrm{~s}$, $\mathbf{c}$ oil entering but not spreading at air/surfactant interface after $300 \mathrm{~s}$, and d Lamellae weakening, detachment and collapse prevented in presence of LB after $600 \mathrm{~s}$ 


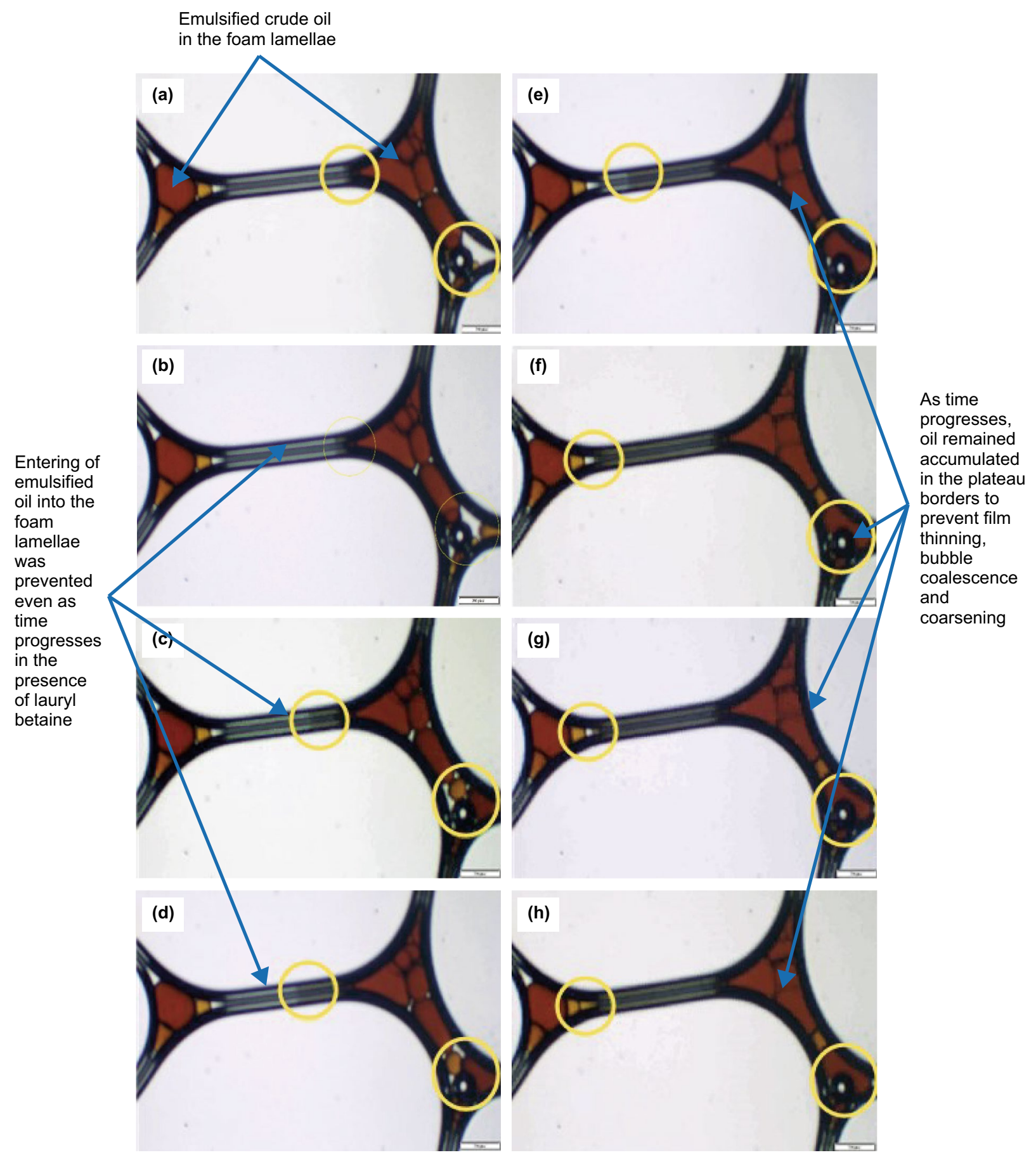

Fig. 16 A 91 surfactant foam at 95\% foam quality in the presence of oil showing a the presence of emulsified oil in plateau borders at $95 \%$ foam quality, and oil remained in plateau borders to prevent foam collapse at b $120 \mathrm{~s}, \mathbf{c} 240 \mathrm{~s}, \mathbf{d} 360 \mathrm{~s}, \mathbf{e} 480 \mathrm{~s}, \mathbf{f} 600 \mathrm{~s}, \mathbf{g} 720 \mathrm{~s}$, and h $840 \mathrm{~s}$

destabilization effects on AOS-stabilized foam at both foam qualities compared to the AOS-LB foam. The spreading of oil on the liquid lamella in the foam film region was more detrimental to the AOS foam film stability compared to the AOS-LB foam. Formation of smaller oil droplets has been reported to be detrimental to foam stability, due to the capacity of the emulsified oil to be transported to plateau borders and even thinnest lamellae. However, foam collapse was prevented in the presence of LB as the oil droplets were unable to spread and penetrate the gas-liquid interface of foam (Schramm and Novosad 1990, 1992).

Generally, the foam lamella having the foam booster (LB) was more resistant and stable compared to the conventional surfactant-stabilized foam. These results are consistent with 


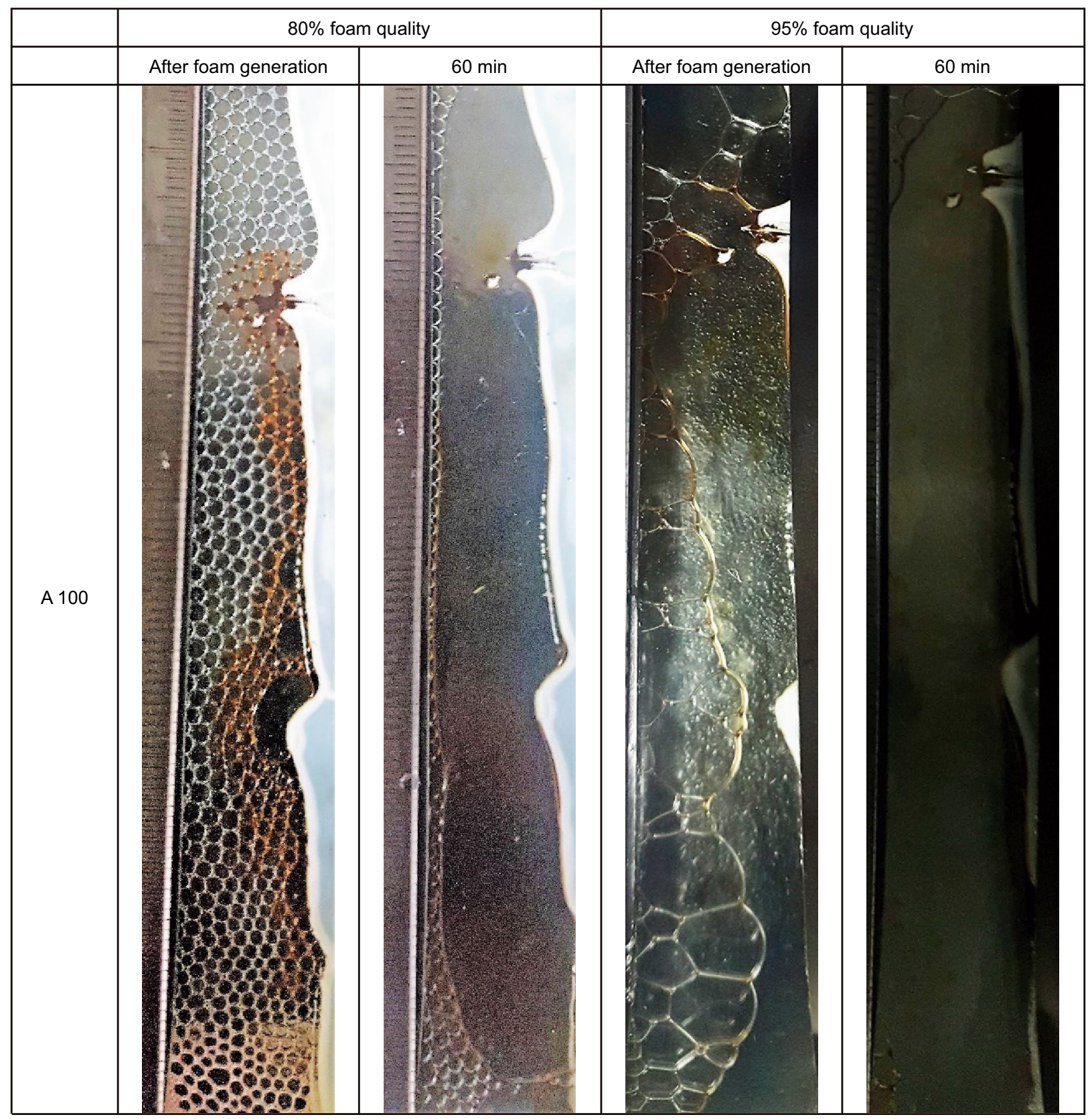

Fig. 17 Static stability of A 100 surfactant foam in the presence of oil at $80 \%$ and $95 \%$ foam qualities and different time intervals in the HeleShaw cell

the literature (Basheva et al. 2000; Cui 2014; Osei-Bonsu et al. 2015). Durable and improved surface-active complex was formed from the synergistic interaction of the anionic surfactant molecules (AOS) and foam booster (LB). The electric attraction between the anionic surfactant and cationic center in betaine functional group enhances the packing density of the surface-active species at the air-water interface (Li et al. 2012; Wang et al. 2013; Cui 2014). The higher packing density of surface-active complex at the foam water-air interface enhanced the stability of the AOS-LB foam in the presence of oil (Wang and Zhang 2010).

In previous studies, the enhanced stability of the conventional foams in the presence of betaine have been attributed to the Marangoni effect, due to the electrostatic attraction between the anionic surfactant and the cationic nitrogen (Domínguez et al. 1997; Sakai and Kaneko 2004). Similar phenomenon contributed to the high stability of the AOS-LB foam was observed in the presence of oil in the 2D Hele-Shaw cell in this study. Electrostatic 


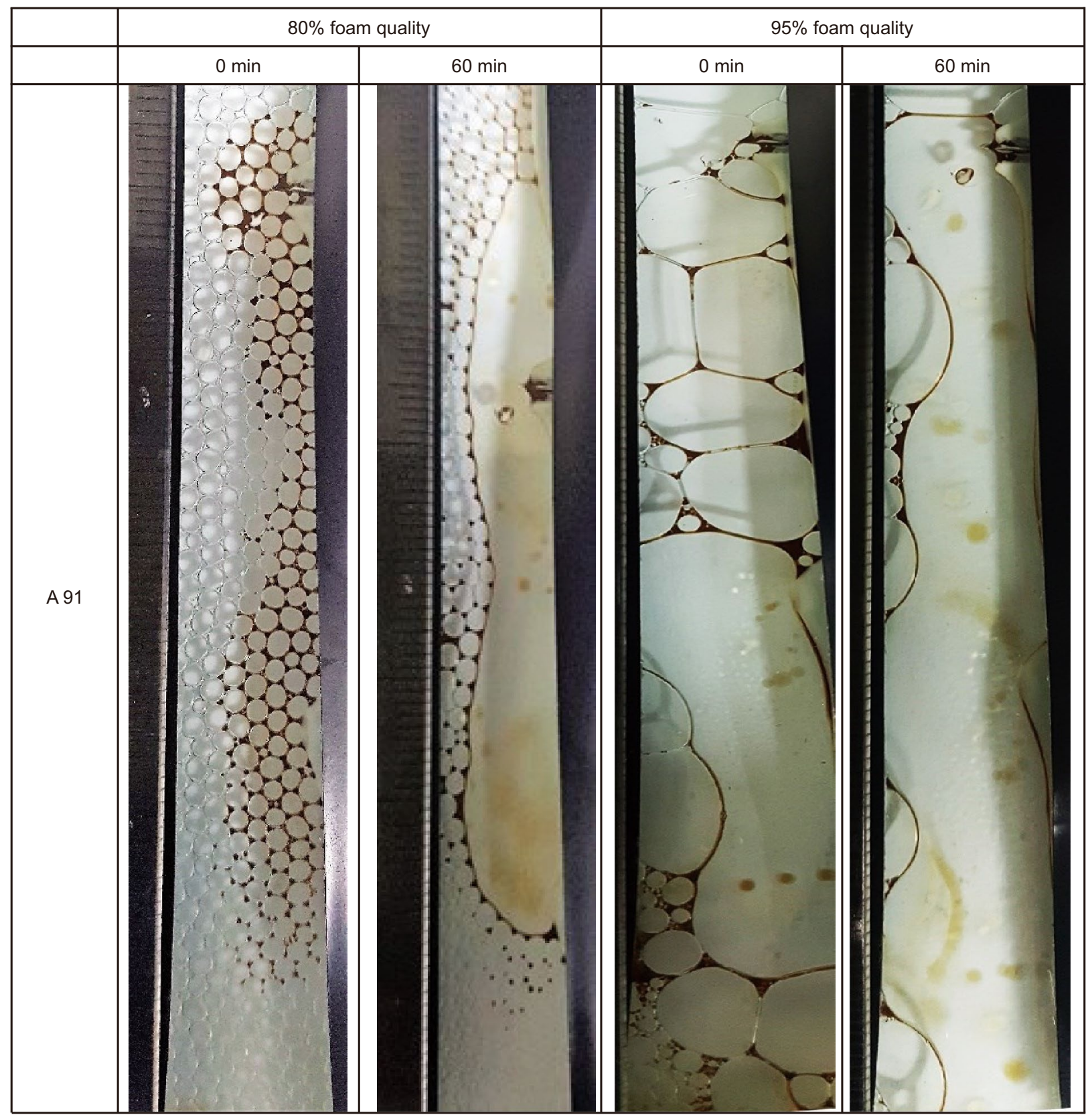

Fig. 18 Static stability of A 91 surfactant foam in the presence of oil at $80 \%$ and $95 \%$ foam qualities and different time intervals in the HeleShaw cell

repulsion can also result from the interaction between the anionic surfactant and anionic center in betaine functional group. The enhanced electrostatic repulsion is expected to increase the disjoining pressure between the two interfaces preventing film coalescence and coarsening (Zhang et al. 2005; Wang et al. 2017). Simulation studies by different researchers showed that mixing of anionic and amphoteric surfactants could result in a denser surfactant monolayer and potentially higher film stability (Wang et al. 2017).

\section{Conclusions}

In this research, the synergistic interaction between a zwitterionic surfactant (lauryl betaine (LB)) and silicon dioxide $\left(\mathrm{SiO}_{2}\right)$ nanoparticles, as well as, the synergistic interaction between LB and the conventional foam-generating surfactants (alpha olefin sulfonate and sodium dodecyl sulfate) were explored for stable foam generation. The purpose is to identify the best conditions for optimum utilization of LB surfactant for foam generation and stabilization at 
representative porous medium (2D Hele-Shaw cell) and high foam qualities.

The results obtained from the research showed that a strong electrostatic interaction between the cationic and anionic centers, in betaine functional group, and the foaming/ stabilizing species, significantly enhanced the foam stability in the absence and presence of crude oil. Higher apparent viscosity was demonstrated during the propagation of AOSLB and SDS-LB foams in the 2D Hele-Shaw cell due to the ease of generation of these foams compared to the $\mathrm{SiO}_{2}-\mathrm{LB}$ foam.

The existence of optimum surfactant concentration for maximum stability of LB foam beyond which the foam stability decreased with increasing percentage of LB was observed. $0.1 \mathrm{wt} \% \mathrm{LB}$ with $\mathrm{SiO}_{2}$ produced higher foam apparent viscosity as compared to the $0.3 \mathrm{wt} \% \mathrm{LB}$ with $\mathrm{SiO}_{2}$. The optimum $\mathrm{SiO}_{2}$ nanoparticle concentration for improving foam apparent viscosity of LB was found to be $0.1 \mathrm{wt} \%$.

The lamella and plateau borders of the AOS-LB foam were resistant to the spreading and dispersion of crude oil compared to the AOS foam. Fundamental investigation of LB-based foam flow characteristics and stability in the 2D Hele-Shaw cell, in the absence and presence of crude oil, is a giant stride toward understanding the foam flow properties and the foam-oil interaction phenomenon in porous media.

Acknowledgements The authors would also like to thank Institute of Hydrocarbon Recovery (IHR), Centre of Research for Enhanced Oil Recovery (COREOR) and Universiti Teknologi PETRONAS for supporting this research.

Open Access This article is licensed under a Creative Commons Attribution 4.0 International License, which permits use, sharing, adaptation, distribution and reproduction in any medium or format, as long as you give appropriate credit to the original author(s) and the source, provide a link to the Creative Commons licence, and indicate if changes were made. The images or other third party material in this article are included in the article's Creative Commons licence, unless indicated otherwise in a credit line to the material. If material is not included in the article's Creative Commons licence and your intended use is not permitted by statutory regulation or exceeds the permitted use, you will need to obtain permission directly from the copyright holder. To view a copy of this licence, visit http://creativecommons.org/licenses/by/4.0/.

\section{References}

Aveyard R, Binks B, Fletcher P, Peck T, Rutherford C. Aspects of aqueous foam stability in the presence of hydrocarbon oils and solid particles. Adv Coll Interface Sci. 1994;48:93-120. https:// doi.org/10.1016/0001-8686(94)80005-7.

Babamahmoudi S, Riahi S. Application of nano particle for enhancement of foam stability in the presence of crude oil: experimental investigation. J Mol Liq. 2018;264:499-509. https://doi. org/10.1016/j.molliq.2018.04.093.

Basheva ES, Ganchev D, Denkov ND, Kasuga K, Satoh N, Tsujii K. Role of betaine as foam booster in the presence of silicone oil drops. Langmuir. 2000;16(3):1000-13. https://doi.org/10.1021/ la990777+.

Bournival G, Du Z, Ata S, Jameson G. Foaming and gas dispersion properties of non-ionic surfactants in the presence of an inorganic electrolyte. Chem Eng Sci. 2014;116:536-46. https://doi. org/10.1016/j.ces.2014.05.011.

Cantat I. Liquid meniscus friction on a wet plate: bubbles, lamellae, and foams. Phys Fluids. 2013;25(3):031303. https://doi. org/10.1063/1.4793544.

Chevallier E, Demazy N, Cuenca A, Chabert M. Correlation between foam flow structure in porous media and surfactant formulation properties. Transp Porous Media. 2019. https://doi.org/10.1007/ s11242-018-01226-2.

Conn CA, Ma K, Hirasaki GJ, Biswal SL. Visualizing oil displacement with foam in a microfluidic device with permeability contrast. Lab Chip. 2014;14(20):3968-77. https://doi.org/10.1039/C4LC0 $0620 \mathrm{H}$.

Cui L. Application of foam for mobility control in enhanced oil recovery (EOR) process. Ph.D. thesis, Rice University; 2014.

Domínguez A, Fernandez A, Gonzalez N, Iglesias E, Montenegro L. Determination of critical micelle concentration of some surfactants by three techniques. J Chem Educ. 1997;74(10):1227. https://doi.org/10.1021/ed074p1227.

Duan X, Hou J, Cheng T, Li S, Ma Y. Evaluation of oil-tolerant foam for enhanced oil recovery: laboratory study of a system of oiltolerant foaming agents. J Pet Sci Eng. 2014;122:428-38. https ://doi.org/10.1016/j.petrol.2014.07.042.

Ettinger R, Radke C. The influence of texture on steady foam flow in Berea sandstone. SPE Reserv Eng. 1992;7(1):83-90. https:// doi.org/10.2118/19688-PA.

Falls A, Hirasaki G, Patzek T, Gauglitz D, Miller D, Ratulowski T. Development of a mechanistic foam simulator: the population balance and generation by snap-off. SPE Reserv Eng. 1988;3(03):884-92. https://doi.org/10.2118/14961-PA.

Farajzadeh R, Andrianov A, Krastev R, Hirasaki G, Rossen WR. Foam-oil interaction in porous media: implications for foam assisted enhanced oil recovery. Adv Coll Interface Sci. 2012;183:1-13. https://doi.org/10.1016/j.cis.2012.07.002.

Farzaneh SA, Sohrabi M. Experimental investigation of $\mathrm{CO}_{2}$-foam stability improvement by alkaline in the presence of crude oil. Chem Eng Res Des. 2015;94:375-89. https://doi.org/10.1016/j. cherd.2014.08.011.

Fei Y, Pokalai K, Johnson R Jr, Gonzalez M, Haghighi M. Experimental and simulation study of foam stability and the effects on hydraulic fracture proppant placement. J Nat Gas Sci Eng. 2017;46:544-54. https://doi.org/10.1016/j.jngse.2017.08.020.

Georgieva D, Cagna A, Langevin D. Link between surface elasticity and foam stability. Soft Matter. 2009;5(10):2063-71. https:// doi.org/10.1039/B822568K.

$\mathrm{Gu}$ M, Mohanty K. Effect of foam quality on effectiveness of hydraulic fracturing in shales. Int J Rock Mech Min Sci. 2014;70:27385. https://doi.org/10.1016/j.ijrmms.2014.05.013.

Hanamertani AS, Pilus RM, Manan NA, Mutalib MIA. The use of ionic liquids as additive to stabilize surfactant foam for mobility control application. J Pet Sci Eng. 2018;167:192-201. https:// doi.org/10.1016/j.petrol.2018.04.010.

Hutchins RD, Miller MJ. A circulating foam loop for evaluating foam at conditions of use. SPE Prod Facil. 2005;20(04):286-94. https ://doi.org/10.2118/80242-PA.

Hutzler S, Peron N, Weaire D, Drenckhan W. The foam/emulsion analogy in structure and drainage. Eur Phys $\mathrm{J}$ E. 2004;14(4):381-6. https://doi.org/10.1140/epje/i2003-10152-1.

Jin F-Y, Wang S, Pu W-F, Yuan C-D, Wang L, Li K-X, et al. Emulsified oil foam for improving the flowability of heavy oil in wellbore under high salinity environments. J Ind Eng Chem. 2016;39:153-61. https://doi.org/10.1016/j.jiec.2016.05.018. 
Kapetas L, Bonnieu SV, Danelis S, Rossen W, Farajzadeh R, Eftekhari A, et al. Effect of temperature on foam flow in porous media. J Ind Eng Chem. 2016;36:229-37. https://doi. org/10.1016/j.jiec.2016.02.001.

Karakashev SI, Manev ED. Correlation in the properties of aqueous single films and foam containing a nonionic surfactant and organic/inorganic electrolytes. J Colloid Interface Sci. 2003;259(1):171-9. https://doi.org/10.1016/S0021 -9797(02)00189-3.

Khatib Z, Hirasaki G, Falls A. Effects of capillary pressure on coalescence and phase mobilities in foams flowing through porous media. SPE Reserv Eng. 1988;3(03):919-26. https://doi. org/10.2118/15442-PA.

Koczo K, Lobo L, Wasan D. Effect of oil on foam stability: aqueous foams stabilized by emulsions. J Colloid Interface Sci. 1992;150(2):492-506. https://doi.org/10.1016/00219797(92)90218-B.

Kraynik AM. Foam flows. Annu Rev Fluid Mech. 1988;20(1):325-57.

Krzan M, Caps H, Vandewalle N. High stability of the bovine serum albumine foams evidenced in Hele-Shaw cell. Colloids Surf A. 2013;438:112-8. https://doi.org/10.1016/j.colsurfa.2013.01.012.

Kumar S, Mandal A. Investigation on stabilization of $\mathrm{CO}_{2}$ foam by ionic and nonionic surfactants in presence of different additives for application in enhanced oil recovery. Appl Surf Sci. 2017;420:9-20. https://doi.org/10.1016/j.apsusc.2017.05.126.

Laskaris G. Effect of surfactant concentration, water treatment chemicals, fatty acids and alcohols on foam behavior in porous media and in bulk. Master thesis, Delft University of Technology; 2015.

Ma K, Liontas R, Conn CA, Hirasaki GJ, Biswal SL. Visualization of improved sweep with foam in heterogeneous porous media using microfluidics. Soft Matter. 2012;8(41):10669-75. https:// doi.org/10.1039/C2SM25833A.

Mannhardt K, Svorst $\varnothing 1$ I. Surfactant concentration for foam formation and propagation in Snorre reservoir core. J Petrol Sci Eng. 2001;30(2):105-19. https://doi.org/10.1016/S0920 -4105(01)00107-3.

Nikolov A, Wasan D, Huang D, Edwards D, editors. The effect of oil on foam stability: mechanisms and implications for oil displacement by foam in porous media. In: SPE annual technical conference and exhibition; 1986: Society of Petroleum Engineers. https://doi.org/10.2118/15443-MS.

Osei-Bonsu K. Foam-facilitated oil displacement in porous media. $\mathrm{Ph} . \mathrm{D}$. dissertation, The University of Manchester (United Kingdom); 2017.

Osei-Bonsu K, Shokri N, Grassia P. Foam stability in the presence and absence of hydrocarbons: from bubble-to bulk-scale. Colloids Surf A. 2015;481:514-26. https://doi.org/10.1016/j.colsu rfa.2015.06.023.

Osei-Bonsu K, Shokri N, Grassia P. Fundamental investigation of foam flow in a liquid-filled Hele-Shaw cell. J Colloid Interface Sci. 2016;462:288-96. https://doi.org/10.1016/j. jcis.2015.10.017.

Pandey S, Bagwe RP, Shah DO. Effect of counterions on surface and foaming properties of dodecyl sulfate. J Colloid Interface Sci. 2003;267(1):160-6. https://doi.org/10.1016/j.jcis.2003.06.001.

Rafati R, Oludara OK, Haddad AS, Hamidi H. Experimental investigation of emulsified oil dispersion on bulk foam stability. Colloids Surf A. 2018;554:110-21. https://doi.org/10.1016/j.colsu rfa.2018.06.043.

Schramm LL, Novosad JJ. Micro-visualization of foam interactions with a crude oil. Colloids Surf. 1990;46(1):21-43. https://doi. org/10.1016/0166-6622(90)80046-7.

Schramm LL, Novosad JJ. The destabilization of foams for improved oil recovery by crude oils: effect of the nature of the oil. J Pet
Sci Eng. 1992;7(1-2):77-90. https://doi.org/10.1016/09204105(92)90010-X.

Simjoo M, Rezaei T, Andrianov A, Zitha P. Foam stability in the presence of oil: effect of surfactant concentration and oil type. Colloids Surf A. 2013;438:148-58. https://doi.org/10.1016/j. colsurfa.2013.05.062.

Singh R, Mohanty KK. Foams with wettability-altering capabilities for oil-wet carbonates: a synergistic approach. SPE J. 2016;21(04):1,126-1,39. https://doi.org/10.2118/175027-PA.

Sun Q, Li Z, Li S, Jiang L, Wang J, Wang P. Utilization of surfactant-stabilized foam for enhanced oil recovery by adding nanoparticles. Energy Fuels. 2014;28(4):2384-94. https://doi. org/10.1021/ef402453b.

Syed AH, Idris AK, Mohshim DF, Yekeen N, Buriro MA. Influence of lauryl betaine on aqueous solution stability, foamability and foam stability. J Pet Explor Prod Technol. 2019;1-7. https://doi. org/10.1007/s13202-019-0652-7.

van der Bent V. Comparative study of foam stability in bulk and porous media. AES/PE. 2014;14-4.

Vikingstad AK, Skauge A, Høiland H, Aarra M. Foam-oil interactions analyzed by static foam tests. Colloids Surf A. 2005;260(1-3):189-98. https://doi.org/10.1016/j.colsu rfa.2005.02.034.

Wang Z-Y, Zhang S-F, Fang Y, Qi L-Y. Synergistic behavior between zwitterionic surfactant $\alpha$-decylbetaine and anionic surfactant sodium dodecyl sulfate. J Surfactants Deterg. 2010;13(4):381-5. https://doi.org/10.1007/s11743-009-1154-2.

Wang X, Wang R, Zheng Y, Sun L, Yu L, Jiao J et al. Interaction between zwitterionic surface activity ionic liquid and anionic surfactant: $\mathrm{Na}^{+}$-driven wormlike micelles. 2013;117(6):188695. https://doi.org/10.1021/jp308016a.

Wang L, Asthagiri D, Zeng Y, Chapman WG. Simulation studies on the role of lauryl betaine in modulating the stability of AOS surfactant-stabilized foams used in enhanced oil recovery. Energy Fuels. 2017;31(2):1512-8. https://doi.org/10.1021/acs. energyfuels.6b03186.

Wang H, Wei X, Du Y, Wang D. Effect of water-soluble polymers on the performance of dust-suppression foams: wettability, surface viscosity and stability. Colloids Surf A. 2019a;568:92-8. https ://doi.org/10.1016/j.colsurfa.2019.01.062.

Wang H, Wei X, Du Y, Wang D. Experimental investigation on the dilatational interfacial rheology of dust-suppressing foam and its effect on foam performance. Process Saf Environ Prot. 2019b;123:351-7. https://doi.org/10.1016/j.psep.2019.01.027.

Xiao S, Zeng Y, Vavra ED, He P, Puerto M, Hirasaki GJ, et al. Destabilization, propagation, and generation of surfactant-stabilized foam during crude oil displacement in heterogeneous model porous media. Langmuir. 2017;34(3):739-49. https://doi. org/10.1021/acs.langmuir.7b02766.

Xu Q, Nakajima M, Ichikawa S, Nakamura N, Roy P, Okadome H, et al. Effects of surfactant and electrolyte concentrations on bubble formation and stabilization. J Colloid Interface Sci. 2009;332(1):208-14. https://doi.org/10.1016/j.jcis.2008.12.044.

Yan W, Miller CA, Hirasaki GJ. Foam sweep in fractures for enhanced oil recovery. Colloids Surf A. 2006;282:348-59. https ://doi.org/10.1016/j.colsurfa.2006.02.067.

Yarveicy H, Javaheri A. Application of lauryl betaine in enhanced oil recovery: a comparative study in micromodel. Petroleum. 2017;5(2):123-7. https://doi.org/10.1016/j.petlm.2017.09.004.

Yekeen N, Idris AK, Manan MA, Samin AM. Experimental study of the influence of silica nanoparticles on the bulk stability of SDS-foam in the presence of oil. J Dispers Sci Technol. 2017a;38(3):416-24. https://doi.org/10.1080/01932 691.2016.1172969.

Yekeen N, Idris AK, Manan MA, Samin AM, Risal AR, Kun TX. Bulk and bubble-scale experimental studies of 
influence of nanoparticles on foam stability. Chin J Chem Eng. 2017b;25(3):347-57. https://doi.org/10.1016/j.cjche .2016.08.012.

Yekeen N, Manan MA, Idris AK, Samin AM. Influence of surfactant and electrolyte concentrations on surfactant Adsorption and foaming characteristics. J Pet Sci Eng. 2017c;149:612-22. https ://doi.org/10.1016/j.petrol.2016.11.018.

Yekeen N, Manan MA, Idris AK, Samin AM, Risal AR. Experimental investigation of minimization in surfactant adsorption and improvement in surfactant-foam stability in presence of silicon dioxide and aluminum oxide nanoparticles. J Pet Sci Eng. 2017d;159:115-34. https://doi.org/10.1016/j.petro 1.2017.09.021.

Yekeen N, Manan MA, Idris AK, Padmanabhan E, Junin R, Samin AM, et al. A comprehensive review of experimental studies of nanoparticles-stabilized foam for enhanced oil recovery. J Pet Sci Eng. 2018a;164:43-74. https://doi.org/10.1016/j.petro 1.2018.01.035.
Yekeen N, Padmanabhan E, Idris AK. A review of recent advances in foam-based fracturing fluid application in unconventional reservoirs. J Ind Eng Chem. 2018b;66:45-71. https://doi. org/10.1016/j.jiec.2018.05.039.

Yekeen N, Padmanabhan E, Idris AK. Synergistic effects of nanoparticles and surfactants on n-decane-water interfacial tension and bulk foam stability at high temperature. J Pet Sci Eng. 2019a;179:814-30. https://doi.org/10.1016/j.petro 1.2019.04.109.

Yekeen N, Padmanabhan E, Idris AK, Ibad SM. Surfactant adsorption behaviors onto shale from Malaysian formations: influence of silicon dioxide nanoparticles, surfactant type, temperature, salinity and shale lithology. J Pet Sci Eng. 2019b;179:841-54. https://doi.org/10.1016/j.petrol.2019.04.096.

Zhang H, Miller CA, Garrett PR, Garrett PR, Raney KH. Lauryl alcohol and amine oxide as foam stabilizers in the presence of hardness and oily soil. J Surfactants Deterg. 2005;8(1):99-107. https ://doi.org/10.1007/s11743-005-0337-3. 